\title{
El rol de Europa del Este en el principio de cohesión de la Unión Europea. Hacia una incompleta integración
}

\author{
Borja Villalgordo Pujalte \\ Manuel Hernández Pedreño \\ Universidad de Murcia
}

\section{Resumen}

La Unión Europea viene promoviendo la consecución de la cohesión social y económica desde sus Tratados Constitutivos. El alcance de este objetivo se ha visto ralentizado por varios motivos, como la entrada de los países de Europa del Este que ha supuesto un aumento de la heterogeneidad en la Unión; o por el diferente impacto de la reciente crisis económica en los distintos países. El objetivo de este trabajo es analizar el proceso de convergencia/ divergencia de los países de Europa del Este en los parámetros socioeconómicos de la Unión Europea que fomentan la cohesión social y económica. La hipótesis de partida es que estos países han mantenido diferentes ritmos de convergencia con la Unión Europea por conformar un bloque heterogéneo, explicado por varios factores: el tiempo de permanencia en la Unión, la influencia de la Unión Soviética, el impacto de la Estrategia Europa 2020 o la situación de la que partían antes de entrar en la Unión. La metodología empleada es mixta, combinando la entrevista a profesionales con el análisis estadístico de los diferentes comportamientos sociales, económicos y políticos en los países de Europa del Este desde el estallido de la crisis hasta ahora. En la comparativa se consideran tres ámbitos de actuación, correspondientes a las principales áreas que conforman la política social y que se integran como objetivos dentro de la Estrategia Europa 2020 (ingresos, trabajo y educación), al tiempo que se incluye la respuesta institucional ofrecida por los diferentes países.

\section{Palabras clave}

Europa del Este; Unión Europea; Estados de Bienestar; cohesión social; crisis económica

Códigos JEL: I18, 128, I32, 138, J18T

\author{
THE ROLE OF EASTERN EUROPE IN THE COHESION PRINCIPLE \\ OF THE EUROPEAN UNION. TOWARDS AN INCOMPLETE \\ INTEGRATION
}

\begin{abstract}
European Union has been promoting the achievement of social and economic cohesion since the Treaty Establishing the European Community. A true embodiment of this goal has been slowed down by several reasons, such as the attachment of Eastern Europe countries that increased the heterogeneity in the European Union; or how European countries dealt with the latest economic recession that took place in 2008. The aim of this paper is to analyse the process of convergence/divergence among Eastern Europe countries and European Union based in a few parameters that foster the economic and social cohesion. The hypothesis is that countries from East of Europe have kept different rates of convergence with the European Union because they shape a heterogeneous group of countries due to several factors: accession year of each country to the European Union, influence of the former Soviet Union, Europe 2020 Strategy's repercussion or the previous situation where these countries come from before being full members of the European Union. In this paper, a mixed methodology was applied, combining interviews with professionals in different fields of knowledge with the statistical analysis of social, economic and political behaviours in the Eastern European Union countries since the outbreak of the crisis until now. In this comparative, three fields of action have been considered as the main areas that compose social policy and are also integrated in the European 2020 Strategy (incomes, work and education), combined with the institutional response offered by these countries.
\end{abstract}

Key Words

Eastern Europe; European Union; welfare states; social cohesion; economic recession

JEL codes: I18, I28, I32, 138, J18T

Fecha de recepción del original: 10 de enero de 2020; versión definitiva: 7 de mayo de 2020.

Borja Villalgordo Pujalte. Departamento de Sociología. Universidad de Murcia. Facultad de Economía y Empresa, Campus de Espinardo s/n, 30100 Murcia. E-mail: borja.moreno@um.es. ORCID ID: 0000-0003-1980-8459.

Manuel Hernández Pedreño. Departamento de Sociología. Universidad de Murcia. Facultad de Economía y Empresa, Campus de Espinardo s/n, 30100 Murcia. Tel.: + 34 868883878. E-mail: manuel@um.es. ORCID ID: 0000-0001-5243-0481 


\title{
El rol de Europa del Este en el principio de cohesión de la Unión Europea. Hacia una incompleta integración
}

\author{
Borja Villalgordo Pujalte \\ Manuel Hernández Pedreño \\ Universidad de Murcia
}

1. Introducción

Durante los años 90 del siglo XX Europa del Este vivió una gran transformación con la caída del bloque socialista. Tras este acontecimiento, surgen o resurgen nuevos países que habían perdido su identidad europea. La reciente entrada de estos estados en la Unión Europea (UE), con una justificación de la adhesión marcada por tintes más políticos que económicos, ha supuesto un aumento en la heterogeneidad de ésta, llegándose a cuestionar la evolución hacia la igualdad y la cohesión económica y territorial que dispone la Unión en sus tratados. Alcanzar esta cohesión es fundamental para la UE, ya que es una constante desde los primeros Tratados de constitución en los que ya se mencionaban objetivos como el de crear un espacio de igualdad o elevar el estado de bienestar de todos los pueblos.

El estallido de la crisis de 2008 que sacudió con fuerza a los países europeos ha supuesto un obstáculo más para la consecución de la convergencia entre Europa del Este y el resto de los países de la UE-15. La adopción de la Estrategia Europa 2020 y de sus ambiciosos objetivos para la década, consideró uno de ellos reducir las grandes brechas que había provocado la crisis en los diferentes países europeos. Sin embargo, a poco tiempo de su conclusión, parece que las metas que se habían propuesto van a quedar lejos de cumplirse.

En este trabajo se lleva a cabo un análisis de la evolución socioeconómica, desde el inicio de la crisis, de los países del Este de Europa que forman parte de la Unión Europea. Ello se hace con la finalidad de verificar si hay procesos de convergencia o divergencia con respecto a la media de la UE-28. Este análisis se realiza con una metodología mixta, que combina datos estadísticos de varias fuentes con entrevistas a profesionales de diversas disciplinas, las cuales aportan perspectivas complementarias sobre el fenómeno. Así, se considera el desarrollo socioeconómico como multidimensional, tomando para este trabajo tres dimensiones estrechamente relacionadas con la Estrategia Europa 2020: renta y desigualdad, educación y empleo; complementado con la respuesta institucional otorgada por los gobiernos de cada país en términos de gasto social.

La premisa básica es que los países de Europa del Este forman un auténtico modelo socioeconómico con características propias, diferenciándose de otros modelos delimitados hasta el momento como el mediterráneo, el continental, el anglosajón o el escandinavo (Sapir, 2006). Además, se considera que estos países no parten de idénticas situaciones ni siguen la misma evolución. Por tanto, se abre la posibilidad de la existencia de submodelos dentro de Europa del Este en función de sus niveles de cohesión social y económica con el resto de la Unión y la tendencia que han seguido durante la última década, donde factores como el año de entrada en la UE, la influencia de la URSS, la localización geográfica o el empleo de los recursos por parte de los Estados podrían ser motivos que sustenten estas diferencias.

\section{Objetivos y metodología}

Partimos de la base de que existen diferentes modelos sociales en Europa, ya definidos, que responden a unas características comunes. Al hablar de modelo para referirnos a la cuestión social es necesario definir la amplitud de éste como un esquema teórico de un sistema, elaborado para hacer más sencilla su comprensión y el estudio y análisis de su comportamiento (Hernández Pedreño y García Luque, 2017). Los países de Europa del Este habrían encontrado escasa inclusión en las clasificaciones clásicas de los modelos sociales europeos (Esping-Andersen, 1993; Ferrera, 1998; Sapir, 2006).

La exclusión social se considera como un fenómeno multidimensional, es decir, se conforma a partir de la acumulación de desventajas sociales en siete dimensiones o esferas vitales: Ingresos, Empleo, Educación, Salud, Vivienda, Relaciones sociofamiliares y Participación (Hernández Pedreño, 2010). De este modo, la política social se entiende como las medidas de protección vinculadas a cada una de estas dimensiones o potenciales áreas de intervención. Esta estructura y denominación de las políticas sociales en siete grandes ámbitos es compartida en gran medida por otros estudios y propuestas, siendo diferenciadas como políticas sectoriales exceptuando 
Relaciones sociofamiliares y Participación, que han sido consideradas como transversales (Fantova, 2014: 115).

El objetivo general de este trabajo radica en analizar los diferentes procesos de integración en la Unión Europea de los países de Europa del Este, a partir del cumplimiento de los objetivos de la Estrategia 2020. En concreto, se contemplan tres de las siete dimensiones mencionadas anteriormente (Ingresos y desigualdad, Empleo y Educación), al ser las dimensiones a las que la Unión ha otorgado un mayor peso en la confección de dicha Estrategia. A tal efecto, son considerados países de Europa del Este y, por tanto, objeto de estudio, los once que se adhirieron a la Unión Europea en el siglo XXI (años 2004, 2007 y 2013): Estonia, Letonia, Lituania, Eslovenia, Eslovaquia, Hungría, Polonia, República Checa, Rumanía, Bulgaria y Croacia. Esta selección se realiza atendiendo a vínculos geográficos, culturales e históricos, quedando fuera del análisis Chipre y Malta.

En este sentido, las hipótesis de partida de este trabajo serían dos. De un lado, se considera que existe un verdadero modelo socioeconómico de los países de Europa del Este que responde a aspectos culturales, históricos, socioeconómicos e ideológicos comunes. De otro lado, se parte de la base de que estos países no están evolucionando al mismo ritmo y se encuentran en procesos de integración con la Unión Europea muy diferentes. El avance en la consecución de los objetivos de la Estrategia Europea 2020 conllevaría un mayor nivel de integración y, así, habría un grupo de países que sí se estarían acercando a los estándares de la UE-28 y otros que se estarían alejando, cuestionando la filosofía de igualdad y cohesión entre países que inspira a la Unión en sus políticas de actuación. Factores como el año de entrada a la UE, su participación o no en la unión monetaria, el grado de vinculación con la extinta Unión Soviética o su proximidad geográfica y vinculación con otros países podrían ser las causas que estuvieran detrás de las diferencias en los procesos de integración.

El estudio se realiza desde una doble perspectiva, cuantitativa y cualitativa, pues se combina información estadística con entrevistas en profundidad, realizadas durante el primer semestre de 2019 a expertos de diferentes áreas de estudio. En ellas se siguió un guion semiestructurado en dos bloques: el primero sobre la situación socioeconómica actual de los países de Europa del Este miembros de la UE; y el segundo sobre la evolución y las tendencias que se atisban de estos países. El perfil de los profesionales o expertos entrevistados se incluye en el Cuadro 1.

Cuadro 1. Perfil profesional de los expertos entrevistados

\begin{tabular}{|l|l|l|}
\hline Perfil & Área de conocimiento & \multicolumn{1}{c|}{ Especialidad } \\
\hline E1 & Economía & Economía Mundial \\
\hline E2 & Economía & $\begin{array}{l}\text { Fundamentos del análisis } \\
\text { económico }\end{array}$ \\
\hline E3 & Sociología & Globalización y UE \\
\hline E4 & Derecho & Derecho de la UE \\
\hline
\end{tabular}

Fuente: elaboración propia
La metodología cuantitativa empleada es la comparación de los diferentes comportamientos sociales, económicos y políticos en estos países con respecto a la media de la UE-28, tomando para ello los años 2008 y 2018. Todo ello se realiza bajo el prisma del principio de cohesión económica y social articulado en el Tratado de Funcionamiento de la Unión Europea y considerando el alcance de los objetivos de la Estrategia Europa 2020 como valoraciones de la integración en las políticas europeas. Así, los ámbitos de actuación considerados se corresponden con tres de las principales áreas que conforman la política social (ingresos/desigualdad, trabajo y educación), a las que la Unión ha concedido especial importancia a la hora de elaborar la Estrategia 2020. Respecto a la selección de indicadores de tipo output, de cada ámbito se han seleccionado tres, siendo uno de ellos el vinculado al objetivo de la estrategia (tasa de empleo, tasa AROPE y abandono educativo temprano). Además, se enfrentan con la respuesta institucional que cada país ofrece en función de los resultados en términos de gasto social.

3. Estrategia Europa 2020 y modelos sociales en la Unión Europea

Desde los orígenes de la Unión Europea (UE) han existido grandes disparidades territoriales y demográficas que han supuesto obstáculos a la integración y desarrollo en Europa. Con la promulgación del Acta Única Europea de 1986, la cohesión económica y social pasa a ser una competencia de la Unión, ampliada a una tercera dimensión, la territorial, con el Tratado de Lisboa de 2008. De este modo, la cohesión pasa a ser un principio orquestador de la acción comunitaria. El discurso pronunciado por Jacques Delors, antiguo presidente de la Comisión Europea, ante el Parlamento Europeo en 1987 vendría a fortalecer esta idea:

Hay que dejar de considerar a los instrumentos comunitarios como meros elementos de compensación financiera. Éstos están llamados a desempeñar, junto con las políticas nacionales y regionales y en armonía con ellas, un importante papel en la convergencia de las economías (Delors, 1993).

El principio de cohesión encuentra su programación legal en el Título XVIII del Tratado de Funcionamiento de la Unión Europea en los artículos 174 a 178. En ellos se dispone que la UE desarrollará y proseguirá su acción encaminada a reforzar su cohesión económica, social y territorial. Pese a no aparecer completamente acotado en los textos comunitarios básicos, el concepto de cohesión económica y social apunta hacia una visión mucho más amplia de la evolución de las disparidades entre regiones, incluyendo componentes sociales, poblacionales, de desempleo, de capacidad innovadora, entre otros (Cuadrado y Marcos, 2005: 63). 
En el año 1995, se hace efectiva la admisión en la UE de Austria, Finlandia y Suecia, quedando conformada una UE-15 constituida por un grupo de países que formaban un bloque homogéneo. Esto cambiaría con la admisión de los llamados PECO o Países de Europa Central y Oriental. En 2004, da inicio un proceso de integración sin precedentes en la esfera europea con la admisión de 10 nuevos países, 8 de ellos pertenecientes a los PECO: Eslovenia, Eslovaquia, Estonia, Hungría, Letonia, Lituania, Polonia y República Checa. En 2007 les Ilegaría el turno a Bulgaria y Rumanía, finalizando la expansión hacia el Este con la admisión de Croacia en el año 2013. Cuando se adhirieron estos países, su realidad social y económica distaba bastante de la del resto de países europeos. Esta ampliación ha sido y sigue siendo un gran reto para la UE, ya que implicó un aumento de la heterogeneidad con respecto a la UE-15 (Sánchez de Gómez, 2011).

El objetivo europeo de consecución de una completa cohesión social y económica entre los territorios se ha visto afectado y ralentizado por la gran recesión económica que azotó Europa en 2008 y que ha supuesto una nueva reconfiguración de los países europeos a raíz de las medidas de austeridad impuestas en los estados. La crisis ha sacudido las bases económicas, sociales e ideológicas sobre las que se sustentaban los diferentes modelos de estado social europeos (Hernández Pedreño y García Luque, 2017; Sanahuja, 2012). Si bien, con dispares repercusiones, dependiendo de los niveles iniciales de desarrollo económico o de la adhesión en su día a la eurozona (Observatorio Metropolitano de Madrid, 2014).

En este contexto se sitúa la adopción de la Estrategia Europa 2020, como la estrategia de crecimiento adoptada por la Unión Europea para la década 2010-2020. La crisis ha conllevado el sacrificio de años de progreso económico y social y ha mostrado las debilidades estructurales que adolecía la economía europea (Comisión Europea, 2010: 3). La UE propone a través de una serie de objetivos la consecución de un crecimiento con altos niveles de empleo, de productividad y de cohesión social. Se convertía así en un ambicioso proyecto que, a poco tiempo de su evaluación final, todo parece indicar que sus objetivos no se van a materializar.

Tras la experiencia negativa de la Estrategia de Lisboa del año 2000, la Estrategia 2020 nació con visas de ser vinculante para los Estados Miembros, aunque no se materializó. Esto se ha acabado traduciendo en una falta de compromiso por parte de los países para llevar a cabo los objetivos, tal y como han establecido los primeros informes de seguimiento de la Comisión Europea, aludiendo a la crisis como una de las causas de este incumplimiento. Además, la falta de atención a las regiones en este plan de crecimiento (Farinós, 2008; Lois, Feal y Carril, 2013) supone un problema para el logro de una autentica cohesión social y económica.

Como señala Moreno (2007 y 2017), el término Modelo Social Europeo (MSE) se emplearía para definir un proyecto político sustentado en la solidaridad colectiva (redistribución), la equidad social (igualdad) y la eficacia productiva (optimización). Sería esta una visión común que comparten la mayor parte de países europeos relacionados con un nivel y calidad de vida determinados por unos estándares legitimados por el conjunto social. El objetivo estratégico del MSE radicaría en al- canzar el crecimiento sostenido y sostenible sobre la base de la cohesión social (Moreno y Serrano, 2007). Este MSE pretende proporcionar identidad y unidad social en la mayoría de los Estados Miembros de la UE (Calatrava, 2018), ya que contrasta con otros sistemas socioeconómicos basados en el individualismo representado por el modelo americano. En este sentido, las sociedades europeas consideran que el Estado debe ser un Estado de Bienestar, responsable de llevar a cabo una serie de políticas sociales dirigidas a mejorar las condiciones de vida de la ciudadanía y a mantener la igualdad de oportunidades y la cohesión social.

No obstante, la existencia de un MSE ha sido ampliamente cuestionada y criticada (Aja, 2014; Campos, 2009; Moreno, 2012; Observatorio Metropolitano, 2011; Paramio, 2009; Shackleton, 2009; Sanahuja, 2012). Para unos, la idea de MSE puede ser vista como una mera aspiración política (Shackleton, 2009: 72). Para otros, es claro que la UE experimenta una crisis profunda que afecta a su racionalidad, legitimidad, relevancia y viabilidad, señalando su rigidez y disfuncionalidad para hacer frente a las urgencias de la crisis y buscar acomodo en el sistema global (Sanahuja, 2012: 51). Desde esta perspectiva, por tanto, se alude a la necesidad de implementar importantes cambios, que permitan confluir política y socialmente (Aja, 2014).

De este modo, no se puede hablar claramente de un modelo social único en Europa, sino de características y valores comunes entre los países europeos (Mulas-Granados, 2009: 23). Esta diversidad de modelos sociales europeos ha sido comúnmente aceptada por numerosos autores (Esping-Andersen, 1993; Ferrera, 1998), siendo Sapir (2006), uno de los más recientes, el que establece la existencia de cuatro modelos sociales europeos, basándose en los niveles de eficiencia y equidad a partir de la situación del mercado de trabajo y de la protección social. Así, Sapir diferencia entre el modelo continental (elevada equidad y baja eficiencia), el anglosajón (baja equidad y elevada eficiencia), el nórdico (elevada equidad y eficiencia) y el mediterráneo (baja equidad y eficiencia).

Los países de Europa del Este han sido incluidos en estudios recientes como modelo de Estado de Bienestar con características propias. Moreno (2017) denomina al modelo del bloque de países del Este como el régimen postcomunista del bienestar, planteando dudas sobre su futura convergencia, destacando la existencia de diferentes trayectorias que abrirían la posibilidad a la existencia de submodelos sociales dentro del bloque del Este.

Asimismo, Calzada, Gómez-Garrido, Moreno y MorenoFuentes (2013) realizan un análisis de la relación entre la distribución de valores en la ciudadanía de los países europeos y los principios del sistema de protección social de los diferentes países. Con ello obtienen una agrupación de los países de Europa en función de esta congruencia entre valores y principios, diferenciando un bloque bastante homogéneo compuesto por los países de Europa Occidental y del Norte, y otro más heterogéneo formado por varios países de Europa del Este y del Sur, en el que destacan la existencia de varios subgrupos. Distinguen, además, la percepción que tienen los ciudadanos de los países de Europa del Este y del Sur frente a los de Europa del Norte, continental y anglosajona: para los primeros el 
Estado de Bienestar es un instrumento para la redistribución económica y el mantenimiento del orden social, mientras que para los últimos es un promotor de la igualdad económica y defensor de los derechos individuales.

4. Convergencia/divergencia en la Unión Europea según ámbitos de actuación

En este epígrafe se analizan los factores que pueden explicar la convergencia o divergencia entre los distintos países que conforman el bloque de Europa del Este, así como entre éstos y la UE-28. El estudio estará dividido en tres bloques de estudio. Se inicia con una contextualización demográfica y económica, para continuar con un análisis del contexto social, focalizando en las principales áreas de la intervención pública (empleo, educación y pobreza) en perspectiva con la media de la UE-28 y los objetivos perseguidos por la Estrategia Europa 2020. Por último, estos resultados serán considerados bajo el prisma de la respuesta institucional otorgada por cada país en términos de gasto social per cápita.
Como resumen de la situación socioeconómica de los países de Europa del Este, podemos considerar el Índice de Desarrollo Humano (IDH). Elaborado anualmente por la Organización de las Naciones Unidas desde 1990, el IDH ha sido generalmente aludido como la medida que sintetiza los factores que componen el desarrollo humano, definido como el proceso de incrementar las posibilidades de elección de las personas (Informe, 1990). Este indicador concentra tres aspectos fundamentales de la vida humana como son la longevidad, el conocimiento y el PIB per cápita como medio necesario para acceder a un nivel de vida decente. A pesar de sus limitaciones, reconocidas por los propios autores, y de críticas hacia la forma de interpretación de este indicador y del modelo estadístico empleado para su cálculo (Castles, 1998), la condensación de una ingente cantidad de información relacionada con fenómenos multidimensionales en un solo índice supone una relevante herramienta de evaluación del desarrollo de los países (Mancero, 2001).

Como muestra el Gráfico 1, en todos los países de Europa del Este miembros de la UE-28 se produce durante el periodo 2001-2017 un aumento considerable del IDH. No obstante, también se mantienen importantes distancias entre los países mejor posicionados, como Eslovenia o República Checa y los que alcanzan menores valores, como Bulgaria o Rumanía. Así, a pesar de la convergencia, pues las distancias entre países se hacen menores, se mantienen heterogéneos niveles de desarrollo socioeconómico.

Gráfico 1. Índice de Desarrollo Humano en Europa del Este. 2001, 2010 y 2017

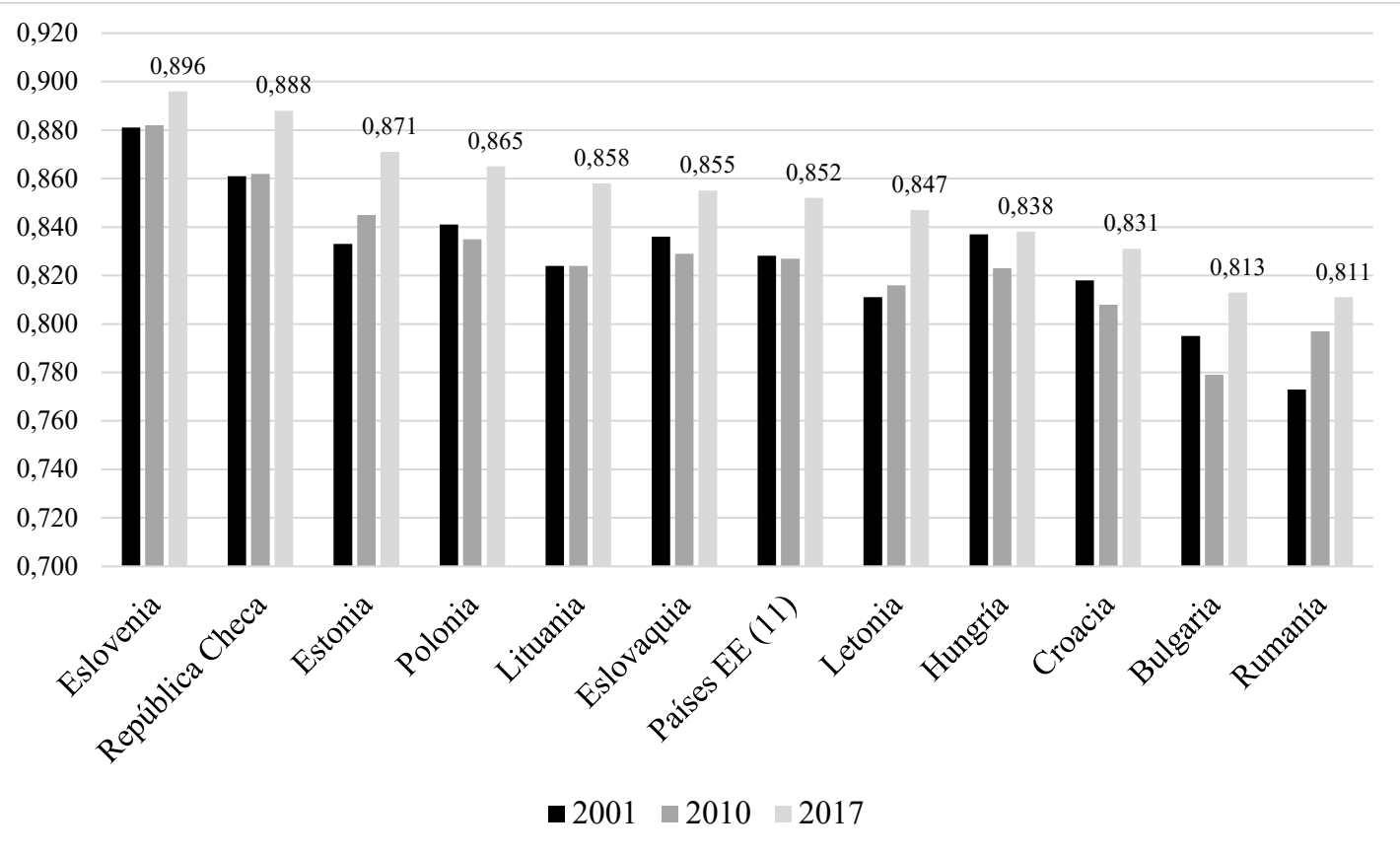

Fuente: Informe sobre Desarrollo Humano de las Naciones Unidas. 
Cuadro 2. Población y Población rural (\%) en países de Europa del Este en UE-28, 2008 y 2018

\begin{tabular}{|l|c|c|c|l|c|c|c|}
\hline \multirow{2}{*}{ País } & \multicolumn{3}{|c|}{ Población } & \multicolumn{3}{c|}{ País } & \multicolumn{3}{c|}{ Población rural } \\
\cline { 2 - 4 } \cline { 7 - 9 } & 2008 & 2018 & $\begin{array}{c}\text { TMAA (\%) } \\
2008-20018\end{array}$ & & 2008 & 2018 & $\begin{array}{c}\text { TMAA (\%) } \\
2008-20018\end{array}$ \\
\hline UE-28 & 500.297 & 512.379 & 0,2 & UE-28 & 26,1 & 26,9 & 0,3 \\
\hline Polonia & 38.115 & 37.977 & 0,0 & Estonia & 51,0 & 31,8 & $-4,6$ \\
\hline Rumanía & 20.635 & 19.531 & $-0,5$ & Bulgaria & 54,1 & 31,9 & $-5,1$ \\
\hline República Checa & 10.343 & 10.610 & 0,3 & Hungría & 47,7 & 33,0 & $-3,6$ \\
\hline Hungría & 10.045 & 9.778 & $-0,3$ & República Checa & 40,5 & 36,0 & $-1,2$ \\
\hline Países de EE (11) & 9.554 & 9.329 & $-0,2$ & Letonia & 49,7 & 37,2 & $-2,9$ \\
\hline Bulgaria & 7.518 & 7.050 & $-0,6$ & Croacia* & 47,4 & 38,4 & $-2,1$ \\
\hline Eslovaquia & 5.376 & 5.443 & 0,1 & Países de EE $(11)$ & 49,4 & 39,8 & $-2,1$ \\
\hline Croacia & 4.312 & 4.105 & $-0,5$ & Polonia & 45,9 & 41,1 & $-1,1$ \\
\hline Lituania & 3.213 & 2.809 & $-1,3$ & Eslovaquia & 40,3 & 42,7 & 0,6 \\
\hline Eslovenia & 2.010 & 2.067 & 0,3 & Rumanía & 61,7 & 45,7 & $-3,0$ \\
\hline Letonia & 2.192 & 1.934 & $-1,2$ & Eslovenia & 46,7 & 45,7 & $-0,2$ \\
\hline Estonia & 1.338 & 1.319 & $-0,1$ & Lituania & 58,2 & 54,3 & $-0,7$ \\
\hline
\end{tabular}

${ }^{*}$ Croacia presenta datos desde 2009.

Fuente: Eurostat, EU-SILC Survey.

Cuadro 3. Población de 65 años o más y población extranjera en países de Europa del Este en UE-28, 2008 y 2018 (\%)

\begin{tabular}{|c|c|c|c|c|c|c|c|}
\hline \multirow[b]{2}{*}{ País } & \multicolumn{3}{|c|}{ Población 65 años o más } & \multirow{2}{*}{ País } & \multicolumn{3}{|c|}{ Población extranjera } \\
\hline & 2008 & 2018 & $\begin{array}{c}\text { TMAA (\%) } \\
2008-20018\end{array}$ & & 2008 & 2018 & $\begin{array}{c}\text { TMAA (\%) } \\
2008-20018\end{array}$ \\
\hline Eslovaquia & 12,1 & 15,5 & 2,5 & Estonia & 17,1 & 14,9 & $-1,4$ \\
\hline Polonia & 13,5 & 17,1 & 2,4 & Letonia & 18,5 & 14,1 & $-2,7$ \\
\hline Rumania & 15,4 & 18,2 & 1,7 & UE-28 & 7,5 & 9,0 & 1,8 \\
\hline Hungría & 16,2 & 18,9 & 1,6 & Eslovenia & 3,4 & 5,9 & 5,7 \\
\hline Países de EE (11) & 16,1 & 19,0 & 1,7 & República Checa & 3,4 & 4,9 & 3,7 \\
\hline República Checa & 14,6 & 19,2 & 2,8 & Países de EE (11) & 4,3 & 4,3 & 0,0 \\
\hline Eslovenia & 16,3 & 19,4 & 1,8 & Hungría & 1,8 & 1,7 & $-0,6$ \\
\hline Lituania & 17,0 & 19,6 & 1,4 & Eslovaquia & 0,8 & 1,3 & 5,0 \\
\hline Estonia & 17,5 & 19,6 & 1,1 & Croacia*** & 0,7 & 1,3 & 6,4 \\
\hline UE-28 & 17,1 & 19,7 & 1,4 & Bulgaria & 0,5 & 1,2 & 9,1 \\
\hline Croacia & 17,8 & 20,1 & 1,2 & Lituania & 1,0 & 1,0 & 0,0 \\
\hline Letonia & 17,6 & 20,1 & 1,3 & Polonia & 0,2 & 0,6 & 11,6 \\
\hline Bulgaria* & 17,8 & 21,0 & 1,7 & Rumanía* & 0,4 & 0,6 & 4,1 \\
\hline Dist. media UE & 1,0 & 0,7 & $-4,2$ & Dist. media UE & 3,2 & 4,7 & 3,9 \\
\hline Dist. países EE & 5,7 & 5,5 & $-0,4$ & Dist. países EE & 18,3 & 14,3 & $-2,4$ \\
\hline
\end{tabular}

*Rumanía presenta datos desde 2012; **Croacia presenta datos desde 2013.

Fuente: Eurostat. Demography and migration. 


\subsection{Contexto demográfico}

La UE-28 cuenta en 2018 con algo más de 500 millones de habitantes (Cuadro 2), formada por países de muy diverso tamaño donde Europa del Este representa un $20 \%$ de esa masa poblacional. La magnitud demográfica de los países del Este interesa porque puede influir en la capacidad de los países en términos de paliar o minimizar efectivamente los efectos no deseados de una recesión económica (Hernández Pedreño y García Luque, 2017).

El crecimiento poblacional en la UE-28 de 2008 a 2018 es muy bajo, apenas un 0,2\% anual. Aun así, es superior a la del bloque de países de Europa del Este que son contrarios a esta dinámica. Solo tres países crecen a un ritmo similar al de la Unión (República Checa, Eslovenia y Eslovaquia) mientras que el resto decrecen o se estancan. Es importante mencionar la gran variedad de tamaños de estos países, donde Polonia cuenta con cerca de 40 millones de habitantes y Estonia apenas supera el millón.

Al analizar los grados de evolución de factores económicos y sociales, dentro de la demografía de un país tiene especial importancia el porcentaje de población que vive en zonas rurales. Estos núcleos de población suelen tener un menor desarrollo económico, un mayor riesgo de pobreza al no tener los mismos servicios que un núcleo urbano ni las mismas coberturas sociales y un mercado de trabajo más débil (Malgesini,
2017). Es importante saber a qué nos referimos cuando hablamos de población rural o de área rural, ya que cada país utiliza su propia metodología. En este sentido, la Comisión Europea (2018) parte de celdas de un kilometro cuadrado que divide en función de la densidad de población en centros urbanos, agrupaciones urbanas o celdas rurales. A partir de esa primera clasificación, si un $50 \%$ de la población de una unidad administrativa (como podría ser un municipio en España) vive en celdas rurales, ese municipio se considera área rural.

Se observa un elevado porcentaje de población rural que denota una falta de urbanización en los países de Europa del Este con respecto a la media europea, pese a que la tendencia es a la concentración en ciudades por la evolución mostrada en la última década. Lituania es el país de toda la Unión con mayor población viviendo en áreas rurales correspondiendo esta a más del 50\% de la población total.

La estructura de la población por edades (Cuadro 3) puede ser un condicionante del modelo social. Una población envejecida demandará un mayor gasto social, especialmente en ciertas áreas como las pensiones o la sanidad y lo hará, además, sin una efectiva aportación al mercado de trabajo.

El envejecimiento de la población es sin duda uno de los grandes retos que afrontan las sociedades europeas del siglo XXI. En cómo se adapten a esta evolución estará la clave para desarrollar una mayor extensión de la cohesión social entre generaciones. Pese a suponer un desafío y un factor de riesgo para la conservación del Estado de Bienestar, lo cierto es que el envejecimiento de la población se considera como un logro

Cuadro 4. PIB per cápita (€PPA) y Ratio S80/S20 en países de Europa del Este en UE-28, 2008 y 2018

\begin{tabular}{|c|c|c|c|c|c|c|c|}
\hline \multirow[b]{2}{*}{ País } & \multicolumn{3}{|c|}{ PIB per cápit } & \multirow[b]{2}{*}{ País } & \multicolumn{3}{|c|}{ Ratio S80/S20 } \\
\hline & 2008 & 2017 & $\begin{array}{c}\text { TMAA (\%) } \\
2008-20017\end{array}$ & & 2008 & 2018 & $\begin{array}{c}\text { TMAA (\%) } \\
2008-20018\end{array}$ \\
\hline UE-28 & 25.655 & 29.522 & 1,6 & República Checa & 3,4 & 3,3 & $-0,3$ \\
\hline Chequia & 21.513 & 26.365 & 2,3 & Eslovenia & 3,4 & 3,4 & 0,0 \\
\hline República Checa & 22.964 & 25.059 & 1,0 & Eslovaquia & 3,4 & 3,5 & 0,3 \\
\hline Estonia & 17.698 & 23.374 & 3,1 & Polonia & 5,1 & 4,3 & $-1,7$ \\
\hline Lituania & 16.097 & 23.092 & 4,1 & Hungría & 3,6 & 4,4 & 2,0 \\
\hline Eslovaquia & 18.320 & 22.353 & 2,2 & Croacia & 5,5 & 5,0 & $-0,9$ \\
\hline Países de EE (11) & 16.549 & 21.068 & 2,7 & UE-28 & 5,0 & 5,1 & 0,2 \\
\hline Polonia & 14.212 & 20.506 & 4,2 & Estonia & 5,0 & 5,1 & 0,2 \\
\hline Hungría & 16.060 & 20.212 & 2,6 & Países de EE (11) & 5,1 & 5,3 & 0,3 \\
\hline Letonia & 15.102 & 19.490 & 2,9 & Letonia & 7,3 & 6,8 & $-0,7$ \\
\hline Rumania & 13.022 & 18.456 & 4,0 & Lituania & 6,1 & 7,1 & 1,5 \\
\hline Croacia & 16.113 & 18.135 & 1,3 & Rumania & 7,0 & 7,2 & 0,3 \\
\hline Bulgaria & 10.933 & 14.702 & 3,3 & Bulgaria & 6,5 & 7,7 & 1,7 \\
\hline Dist. media UE & 9.106 & 8.454 & $-0,8$ & Dist. media UE & $-0,1$ & $-0,2$ & 2,7 \\
\hline Dist. países EE & 12.031 & 11.663 & $-0,3$ & Dist. países EE & 3,9 & 4,4 & 1,2 \\
\hline
\end{tabular}

Fuente: Eurostat. Annual national accounts, ESA 2010 \& ILC. 
de los países europeos, fruto de un mayor desarrollo de estas sociedades (Zaidi, 2008).

Se advierte un envejecimiento de la población en toda Europa del Este. Pese a partir de porcentajes distintos en 2008 , en 2018 se ha producido una convergencia con el resto de la UE-28, debido a un ritmo superior de envejecimiento en estos países, situándose alrededor del 19\% (17\%-21\%), con la excepción de Eslovaquia.

Por último, el peso de la población extranjera es prácticamente inexistente en muchos de los países de Europa del Este y notablemente inferior al del resto de la UE-28, en el que solo las repúblicas bálticas de Letonia y Estonia presentan mayores datos (en torno al 15\%).

\subsection{Contexto socioeconómico}

En este apartado se va a realizar una aproximación del estado del contexto social en los países motivo de estudio, basándonos en tres áreas de actuación: ingresos, empleo y educación; y todas ellas bajo el prisma de los objetivos propuestos por la Estrategia Europa 2020 en los tres campos.

\subsection{1. Ámbito de ingresos}

El desarrollo económico es uno de los principales motores de evolución de los estados de bienestar. Teóricamente, implica un aumento de la calidad de vida mediante la reducción de la pobreza, la mejora del sistema educativo y la creación de empleo y mejora de la productividad. Sin embargo, un crecimiento económico acompañado de un aumento de la desigualdad que genere una mayor pobreza relativa da lugar a una gran insatisfacción entre la población y puede llevar a una situación de inestabilidad política que, según varios estudios, reduciría incentivos a la inversión y frenaría ese crecimiento económico (Alesina y Perotti, 1996), además de provocar un aumento en los índices de criminalidad si la desigualdad alcanzara un punto crítico (Enamorado et al., 2016).

EI PIB por habitante (Cuadro 4) se ha tomado normalmente como el indicador más útil para medir el avance hacia la reducción de las diferencias regionales y los estudios de convergencia, además de ser el indicador de referencia para establecer el carácter elegible de las regiones europeas más atrasadas para recibir fondos estructurales (Cuadrado Roura y Marcos Calvo, 2005). Como podemos observar, Europa del Este ha tenido un crecimiento constante, aunque con dispar velocidad. Países como Polonia, Lituania y Hungría han crecido por encima del $4 \%$ anual, mientras que otros como Croacia o Eslovenia apenas han superado el $1 \%$ anual en el periodo. En base a este indicador se podrían establecer tres modelos claramente diferenciados en términos de renta per cápita. En un primer lugar estarían República Checa y Eslovenia como los países con mejores datos, muy cercanos a converger realmente con la UE-28. Un segundo modelo sería el conformado por las tres repúblicas bálticas, Polonia, Hungría y Eslovaquia, como países que, aún alejados de la UE-28, mantienen una tendencia de convergencia. Y, por último, Rumanía, Croacia y Bulgaria se presentarían como los peores países de la Unión en este aspecto, muy alejados del resto de países europeos, con especial preocupación por el caso búlgaro que apenas llegaría al 50\% de la media de la UE.

Sin embargo, el PIB per cápita resulta algo simple para medir adecuadamente los avances hacia una mayor cohesión

Gráfico 2. Tasa AROPE en países de Europa del Este en UE-28 y Objetivo Europa 2020, 2018 (\%)

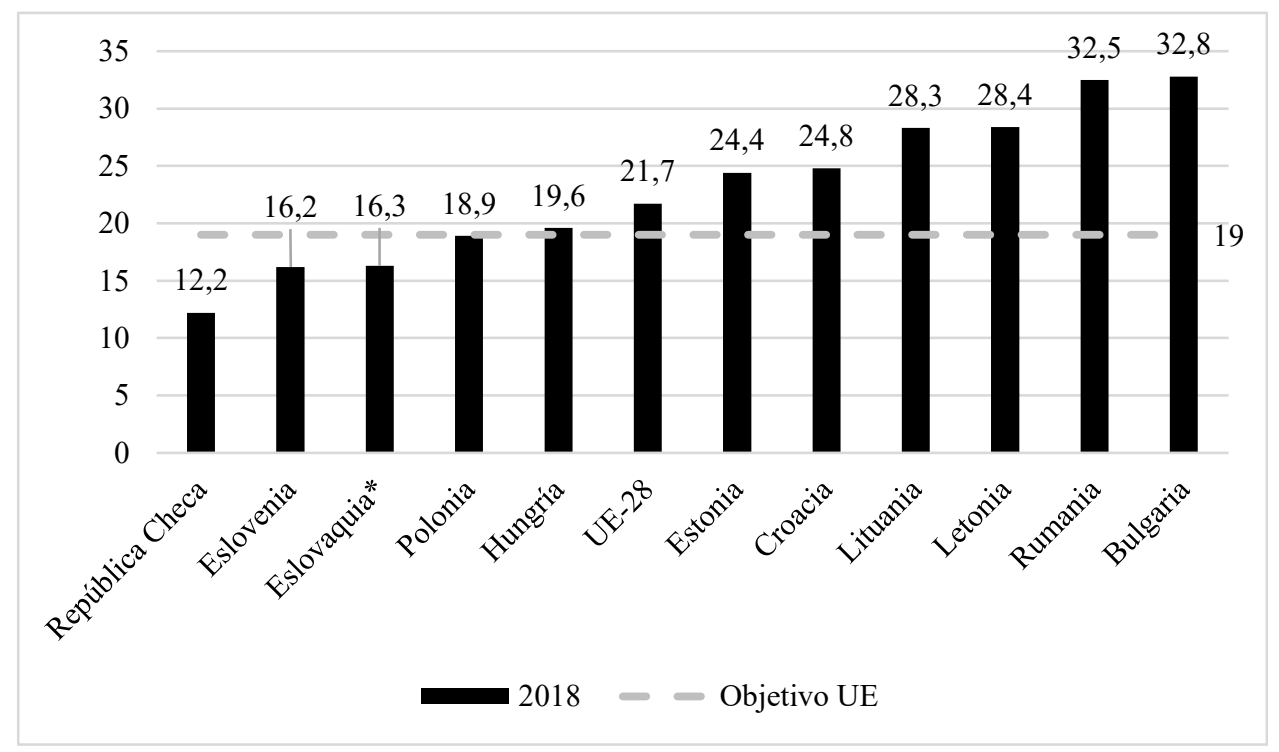

Fuente: Eurostat. Europe 2020 Indicators. 
económica y social. Se hace necesario el empleo de otros indicadores, como la desigualdad de renta expresada por la ratio S80/S20. Como decíamos, un gran desarrollo económico en términos de PIB per cápita que no vaya acompañado de una reducción de la desigualdad es perjudicial para las sociedades.

En torno a esta afirmación, podemos observar la evolución de Hungría y Polonia. Mientras ambos han crecido relativamente deprisa en términos de PIB per cápita durante la última década, mostrando en la actualidad niveles muy similares, la evolución de la desigualdad ha sido diferente en ambos países. Polonia la ha reducido casi en un $2 \%$ anual mientras que, en el caso de Hungría, ha aumentado en un porcentaje superior al 2\% anual. Podemos decir que el crecimiento económico de Polonia, pese a ser muy parecido al de Hungría, ha sido mejor para el avance de la cohesión social y económica que el del país magiar.

La tasa AROPE (Gráfico 2) es un indicador que recoge una visión multidimensional de la exclusión social mediante el empleo de tres variables: pobreza, privación material severa y baja intensidad de trabajo del hogar. La UE incluyó este indicador en la Estrategia Europa 2020 para luchar contra la pobreza y la exclusión social, con el objetivo de reducirla en unos 20 millones de europeos. Esto fue un importante logro con respecto a la anterior Estrategia de Lisboa dado que reconoció su procedencia en varios factores como la precariedad o el desempleo (Arriola, 2014) y materializó cuantitativamente el objetivo de reducción de la pobreza. Sin embargo, la misma Comisión Europea reconoció la imposibilidad de lograr este objetivo un año después de la aprobación de la Estrategia Europa 2020 debido, entre otras razones, a la falta de coordinación con los países miembros a la hora de fijar los objetivos (Comisión Europea, 2011).

Los países de Europa del Este siguen teniendo un mayor porcentaje de población en riesgo de pobreza y exclusión social que el resto de la UE-28, si bien la tendencia es a converger. Tan solo cuatro de los once países del bloque (República Checa, Eslovenia, Eslovaquia y Polonia) consiguen reducir sus tasas AROPE por debajo del máximo que se planteó la Unión en la Estrategia Europa 2020. Rumanía y Bulgaria se vuelven a erigir como los países peor situados, con unas tasas insostenibles, superiores al $30 \%$ de la población. República Checa y Eslovenia vuelven a presentarse como los países líderes del bloque del Este con dos de los mejores datos de toda la Unión.

\subsubsection{Empleo y precariedad laboral}

El pleno empleo siempre fue uno de los objetivos de la Comunidad Económica Europea que ya figuraba en el Tratado de Roma 1957. Sin embargo, la primera toma de consideración por parte de la Unión Europea hacia el empleo como objetivo de acción comunitaria nace en la Cumbre de Luxemburgo (1997), a raíz del Tratado de Ámsterdam de 1997, a través de la creación de la Estrategia Europea de Empleo (EEE). La EEE nació articulada sobre cuatro pilares: empleabilidad, espíritu de empresa, adaptabilidad e igualdad de oportunidades. Con ella, se constata la existencia de nuevas disposiciones jurídicas, como las directivas, que pese a no ser vinculantes perfilan los modelos socioeconómicos y de política social de los Estados, creando lo que podríamos llamar una cultura del empleo (De Pablos y Martínez, 2008).

La Estrategia de Lisboa o Agenda de Lisboa adoptada a principios del año 2000 fue un intento de dar un nuevo impulso a las políticas comunitarias aprovechando una coyuntura económica presumiblemente favorable con la intención de convertirse en diez años en la economia más competitiva y dinámica, con la consecución de un crecimiento económico duradero acompañado de una mejora del empleo y un fortalecimiento de la cohesión social (Consejo Europeo de Lisboa, 2000). Para este fin se adoptan una serie de directrices entre las que destacaban ciertas líneas de actuación como el pleno empleo, el reto tecnológico o la modernización del modelo social europeo.

Tras ello, se introduce el concepto de flexicurity o flexiseguridad en las políticas de actuación de la UE, a raíz del Informe Wim Kok sobre la Agenda de Lisboa en 2004. Esta práctica se debatió por primera vez en el Consejo Informal de Villach (Austria), en el año 2006 y el Libro Verde de la Comisión Europea publicado a finales del año 2006 que aborda la necesidad de introducir este concepto en el Derecho laboral de los países para alcanzar un mercado de trabajo europeo más competitivo (Baviera, 2010). La flexiguridad nació por la necesidad de conseguir un modelo de empleo que aglutinara la necesaria flexibilidad que exigía la competitividad de un nuevo entorno globalizado y tecnológico, la libertad de las personas para escoger y el mantenimiento del modelo social europeo garante de la cohesión social (Miguélez, 2007). Este modelo fue adoptado en mayor o menor medida por todos los Estados, aunque ha sido puesto en duda tras la gran crisis que asoló Europa en el año 2008.

La crisis financiera internacional supuso una severa destrucción del empleo y un empeoramiento de la calidad de éste, así como una gran variedad de respuestas de los diferentes estados que han provocado que una de las notas características en el ámbito del mercado de trabajo sea el desigual impacto que ha tenido en los países de la Unión (Eichhorst, Feli y Marx, 2010). Ello ha supuesto un replanteamiento de los objetivos y de las políticas de actuación de la Unión, reflejándose en la adopción en 2010 de la Estrategia Europa 2020 que tenía como reto inmediato salir de la crisis persiguiendo también el pleno empleo, una gran productividad y reforzar la cohesión social.

La tasa de temporalidad (Cuadro 5) ha sido tomada generalmente como un indicador de la precariedad en el mercado de trabajo, si bien tiene manifestaciones muy dispares en los países europeos. En algunos puede provocar una fuerte inseguridad en el empleo y en otros puede traducirse en un aumento de la flexibilidad laboral motivada por movilidad interna o funcional o a una reducción del tiempo de trabajo que puede ser voluntaria (Miguélez y Prieto, 2008). En el caso de Europa del Este, podemos apreciar unas tasas de temporalidad sensiblemente inferiores a las de la UE-28, exceptuando a Eslovenia, Croacia y Polonia. 
Cuadro 5. Temporalidad y empleo a tiempo parcial involuntario en países de Europa del Este en UE-28, 2008 y 2018 (\%)

\begin{tabular}{|c|c|c|c|c|c|c|c|}
\hline \multirow[b]{2}{*}{ País } & \multicolumn{3}{|c|}{ Tasa de temporalidad } & \multirow{2}{*}{ País } & \multicolumn{3}{|c|}{ Empleo tiempo parcial involuntario } \\
\hline & 2008 & 2018 & $\begin{array}{c}\text { TMAA (\%) } \\
\text { 2008-20018 }\end{array}$ & & 2008 & 2018 & $\begin{array}{c}\text { TMAA (\%) } \\
\text { 2008-20018 }\end{array}$ \\
\hline Rumania & 1,3 & 1,1 & $-1,7$ & Estonia & 13,4 & 5,8 & $-8,0$ \\
\hline Lituania & 2,4 & 1,6 & $-4,0$ & República Checa & 14,0 & 6,5 & $-7,4$ \\
\hline Letonia & 3,4 & 2,7 & $-2,3$ & Eslovenia & 6,8 & 6,5 & $-0,5$ \\
\hline Estonia & 2,4 & 3,5 & 3,8 & Polonia & 18,5 & 15,9 & $-1,5$ \\
\hline Bulgaria & 4,9 & 4,0 & $-2,0$ & Hungría & 28,4 & 22,9 & $-2,1$ \\
\hline Hungría & 7,8 & 7,3 & $-0,7$ & Lituania & 22,4 & 24,4 & 0,9 \\
\hline Eslovaquia & 4,5 & 8,1 & 6,1 & UE-28 & 25,6 & 24,8 & $-0,3$ \\
\hline República Checa & 7,2 & 8,4 & 1,6 & Países de EE (11) & 25,7 & 26,0 & 0,1 \\
\hline Países de EE (11) & 8,2 & 8,8 & 0,7 & Eslovaquia & 23,0 & 26,5 & 1,4 \\
\hline UE-28 & 14,1 & 14,1 & 0,0 & Letonia & 31,3 & 33,1 & 0,6 \\
\hline Eslovenia & 17,3 & 15,7 & $-1,0$ & Croacia & 21,8 & 33,8 & 4,5 \\
\hline Croacia & 12,3 & 19,9 & 4,9 & Rumania & 51,8 & 54,2 & 0,5 \\
\hline Polonia & 26,9 & 24,3 & $-1,0$ & Bulgaria & 51,0 & 56,9 & 1,1 \\
\hline Dist. media UE & 5,9 & 5,3 & $-1,0$ & Dist. media UE & $-0,1$ & $-1,2$ & 32,9 \\
\hline Dist. países EE & 25,6 & 23,2 & $-1,0$ & Dist. países EE & 45,0 & 51,1 & 1,3 \\
\hline
\end{tabular}

Fuente: Eurostat. Labour force survey.

Gráfico 3. Tasa de empleo en Europa del Este en 2018, objetivo nacional y de Europa 2020 (\%)

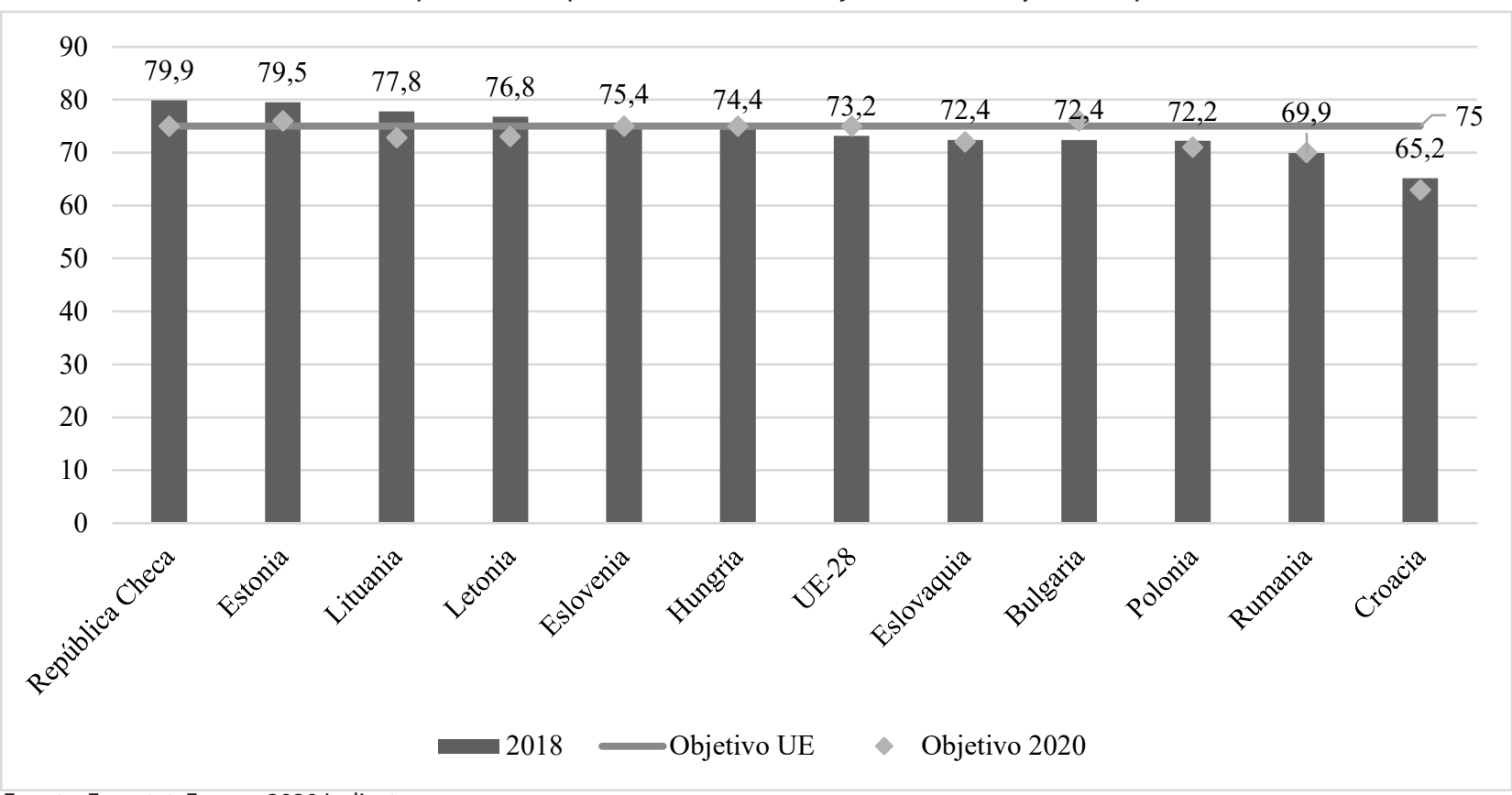

Fuente: Eurostat, Europe 2020 Indicators. 
Cuadro 6. Población con un nivel educativo superior a secundaria obligatoria y con estudios superiores en Europa del Este y UE-28. 2008 y 2018 (\%)

\begin{tabular}{|c|c|c|c|c|c|c|c|}
\hline \multirow{2}{*}{ País } & \multicolumn{3}{|c|}{$\begin{array}{l}\text { Nivel educativo superior a secunda- } \\
\text { ria obligatoria }\end{array}$} & \multirow{2}{*}{ País } & \multicolumn{3}{|c|}{ Población con estudios superiores } \\
\hline & 2008 & 2018 & $\begin{array}{l}\text { TMAA (\%) } \\
\text { 2008-20018 }\end{array}$ & & 2008 & 2018 & $\begin{array}{l}\text { TMAA (\%) } \\
\text { 2008-20018 }\end{array}$ \\
\hline Lituania & 90,4 & 94,8 & 0,5 & Lituania & 30,2 & 41,7 & 3,3 \\
\hline República Checa & 90,9 & 93,9 & 0,3 & Estonia & 34,2 & 41,2 & 1,9 \\
\hline Polonia & 87,1 & 92,4 & 0,6 & Letonia & 24,8 & 33,9 & 3,2 \\
\hline Eslovaquia & 89,9 & 91,7 & 0,2 & Eslovenia & 22,6 & 33,5 & 4,0 \\
\hline Letonia & 85,9 & 90,7 & 0,5 & UE-28 & 24,2 & 32,3 & 2,9 \\
\hline Estonia & 88,4 & 89,2 & 0,1 & Polonia & 19,6 & 30,9 & 4,7 \\
\hline Países de EE (11) & 84,0 & 88,4 & 0,5 & Países de EE (11) & 21,1 & 29,7 & 3,5 \\
\hline Eslovenia & 82,0 & 88,1 & 0,7 & Bulgaria & 22,8 & 28,2 & 2,1 \\
\hline Croacia & 76,7 & 85,1 & 1,0 & Croacia & 16,2 & 25,4 & 4,6 \\
\hline Hungría & 79,6 & 84,9 & 0,6 & Hungría & 19,3 & 25,1 & 2,7 \\
\hline Bulgaria & 77,5 & 82,6 & 0,6 & Eslovaquia & 14,8 & 24,6 & 5,2 \\
\hline Rumania & 75,3 & 78,5 & 0,4 & República Checa & 14,5 & 24,3 & 5,3 \\
\hline UE-28 & 71,3 & 78,1 & 0,9 & Rumanía & 12,8 & 17,8 & 3,4 \\
\hline Dist. media UE & 12,7 & 10,3 & $-2,1$ & Dist. media UE & 3,1 & 2,6 & $-1,8$ \\
\hline Dist. países EE & 15,6 & 16,3 & 0,4 & Dist. países EE & 21,4 & 23,9 & 1,1 \\
\hline
\end{tabular}

Fuente: Eurostat. Education and Training.

El trabajo a tiempo parcial involuntario sí que puede suponer un problema, al tratarse de trabajadores que quieren trabajar a jornada completa, si bien la situación del mercado laboral se lo impide. En este sentido, vemos países como Rumanía y Bulgaria, que tenían una temporalidad muy baja, tienen un porcentaje superior al $50 \%$. Otros como Estonia, República Checa o Eslovenia muestran tres de los mejores datos de la Unión. Esto nos da unos resultados muy dispares y con grandes distancias entre los países de Europa del Este que han ido aumentado durante la última década.

En el Gráfico 3 se muestra la tasa de empleo para los países de Europa del Este en relación con el objetivo establecido por la UE en la Estrategia Europa 2020.

Como muestra el gráfico, una mayoría de países se encuentran por debajo de la meta propuesta, cifrada en un $75 \%$. Si bien, se encuentran relativamente cerca del cumplimiento de este objetivo, con la excepción de Croacia, uno de los países más maltratados por la crisis económica en el ámbito laboral junto con otros del área mediterránea como España o Italia. Cabe hacer una mención especial al caso de República Checa y los resultados que arroja en materia laboral. El escaso porcentaje de empleo a tiempo parcial involuntario combinado con la mayor tasa de empleo de los países de Europa del Este la convierten en un espejo en el que mirarse. Además, poseen la tasa de paro más baja no solo del entorno europeo, sino del mundo, por delante de países como Japón o Islandia.

\subsubsection{Educación}

La educación encuentra su primera referencia expresa en un texto constitutivo europeo en el Tratado de la Unión Europea de 1992 que sucedió a la cumbre de Maastricht, concretamente en el Capítulo 3 que recibe el nombre de "Educación, Formación profesional y juventud". En él se dispone que la Comunidad Europea contribuirá al desarrollo de una educación de calidad fomentando la cooperación entre los Estados Miembros (véase artículo 126.1 TUE 1992). La tendencia del camino hacia la armonización en estos primeros años de política educativa en el ámbito europeo se centra más en equiparar los sistemas y hacerlos compatibles que en igualarlos (Egido, 1996).

Aun así, la UE está demostrando de aquí a un tiempo atrás que la política educativa juega un importante papel en su agenda de actuación, tras demostrarse su correlación con otras áreas de importancia comunitaria, estando estrechamente interrelacionada con dimensiones como ingresos y trabajo (Hernández Pedreño y García Luque, 2017). La población que no alcanza un nivel educativo superior a secundaria obligatoria (Cuadro 6) tiene una mayor probabilidad de acabar en la pobreza y en la exclusión social, ya que no tiene el mismo acceso a puestos de trabajos de calidad, y suele acceder a empleos precarios y mal retribuidos (Formichella y London, 2013). 
Gráfico 4. Abandono Educativo Temprano en países de Europa del Este en UE-28 en 2018, objetivo nacional y de Europa 2020 (\%)

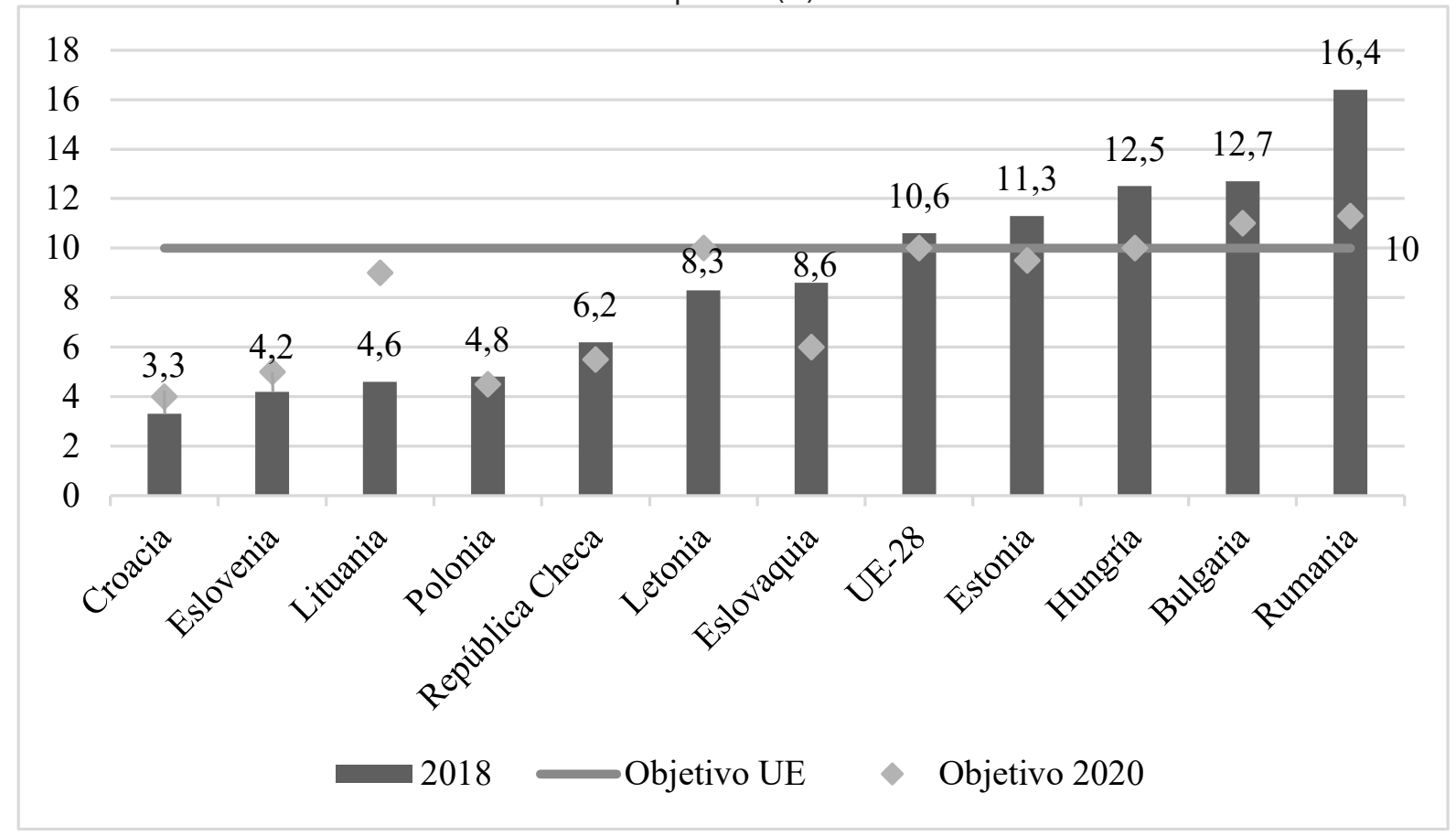

Fuente: Eurostat. Europe 2020 Indicators.

Como podemos ver, los países de Europa del Este presentan unos resultados muy superiores con respecto al resto de la UE-28 en este indicador, llegando al $90 \%$ de la población en una gran mayoría de países, liderando a la Unión en este aspecto. Además, la evolución durante la última década es al alza, llegando algunos países a rondar el 100\% de la población con estudios superiores a secundaria. Volvemos a encontrar a Rumanía y Bulgaria como los que presentan los resultados más bajos de toda Europa del Este, pese a encontrarse por encima de la media de la Unión.

Los niveles de población con estudios superiores a secundaria obligatoria son una clara herencia del sistema comunista, que tenía vocación de ser universalista en todos los niveles de educación. En este sentido, en los países de Europa del Este siempre ha habido un gran capital humano. La UE vio en estos países una fuente de mano de obra cualificada a bajo coste (E3, Sociología).

En cuanto al porcentaje de población con estudios superiores observamos un aumento en todos los países analizados. Podemos encontrar una de las causas en la crisis económica que ha provocado que los jóvenes alarguen su permanencia en el sistema educativo debido al retroceso del empleo. Lo que sí que observamos es una mayor disparidad en los crecimientos en los países de Europa del Este, que han provocado el aumento de las distancias entre ellos. Son las tres repúblicas bálticas, Letonia, Lituania y Estonia, que sí fueron parte de la antigua Unión Soviética, las que muestran los mayores datos.
Rumanía es otra vez el país que se sitúa a la cola del bloque y del conjunto de la UE-28, sin llegar siquiera al $20 \%$ de la población y cada vez más lejos de la convergencia con el resto de Europa.

El abandono educativo temprano (Gráfico 4) está motivado por muy diversas causas, de entre las que cabría destacar la situación de las familias con mayores dificultades económicas, la actitud de éstas al no conceder a la formación la importancia que tiene o a los entornos conflictivos (Comisión Europea, 2009). Reducir el abandono educativo temprano al $10 \%$ fue uno de los objetivos que se marcó Europa en la Estrategia 2020. Además, cada país se propuso un objetivo nacional en la mejora de este indicador.

El Gráfico 4 evidencia una realidad más que satisfactoria para la mayoría de los países de Europa del Este, al haber superado siete de ellos el objetivo marcado por la Unión y con medias que superan ampliamente a las ofrecidas por la UE-28. Rumanía y Bulgaria vuelven a ser el furgón de cola del bloque del Este, si bien el país búlgaro muestra una leve tendencia a converger con el resto de la Unión.

\subsection{Respuesta institucional}

Los gobiernos de cada país tienen la capacidad de promover la mejora de la calidad de vida de los ciudadanos a través 
Cuadro 7. Gasto en protección social y en educación per cápita en países de Europa del Este en UE-28, 2008 y 2017

\begin{tabular}{|c|c|c|c|c|c|c|c|}
\hline \multirow[b]{2}{*}{ País } & \multicolumn{3}{|c|}{ Protección social } & \multirow[b]{2}{*}{ País } & \multicolumn{3}{|c|}{ Educación } \\
\hline & 2008 & 2017 & $\begin{array}{c}\text { TMAA (\%) } \\
2008-20017\end{array}$ & & 2008 & 2017 & $\begin{array}{c}\text { TMAA (\%) } \\
2008-20017\end{array}$ \\
\hline UE-28 & $4.561,70$ & $5.651,90$ & 2,4 & UE-28 & $1.285,20$ & 1398,00 & 0,9 \\
\hline Eslovenia & $2.932,40$ & $3.364,50$ & 1,5 & Eslovenia & $1.143,00$ & 1131,00 & $-0,1$ \\
\hline Estonia & $1.417,10$ & $2.340,90$ & 5,7 & Estonia & 824,80 & 1042,50 & 2,6 \\
\hline Eslovaquia & $1.546,60$ & $2.265,50$ & 4,3 & República Checa & 730,60 & 838,10 & 1,5 \\
\hline República Checa & $1.855,90$ & $2.170,60$ & 1,8 & Letonia & 702,40 & 797,60 & 1,4 \\
\hline Polonia & $1.489,30$ & $2.022,80$ & 3,5 & Lituania & 624,60 & 725,70 & 1,7 \\
\hline Países de EE (11) & $1.469,20$ & $1.902,60$ & 2,9 & Países de EE (11) & 598,70 & 678,00 & 1,4 \\
\hline Hungría & $1.873,50$ & $1.774,30$ & $-0,6$ & Hungría & 570,70 & 640,30 & 1,3 \\
\hline Croacia & $1.496,00$ & $1.690,70$ & 1,4 & Polonia & 541,30 & 602,90 & 1,2 \\
\hline Lituania & $1.235,90$ & $1.663,30$ & 3,4 & Eslovaquia & 432,80 & 592,00 & 3,5 \\
\hline Letonia & $1.007,40$ & $1.615,90$ & 5,4 & Croacia & 515,60 & 556,30 & 0,8 \\
\hline Rumania & 779,70 & $1.114,20$ & 4,0 & Rumania & 303,90 & 271,60 & $-1,2$ \\
\hline Bulgaria & 527,70 & 906,30 & 6,2 & Bulgaria & 195,60 & 260,40 & 3,2 \\
\hline Dist. media UE & $-3.092,50$ & $-3.749,30$ & 2,2 & Dist. media UE & $-686,50$ & $-720,00$ & 0,5 \\
\hline Dist. países EE & $2.404,70$ & $2.458,20$ & 0,2 & Dist. países EE & 947,40 & 870,60 & $-0,9$ \\
\hline
\end{tabular}

Fuente: Eurostat. Government statistics.

Gráfico 5. Relación Abandono Educativo Temprano y el gasto en educación en países de Europa del Este en UE-28, 2017

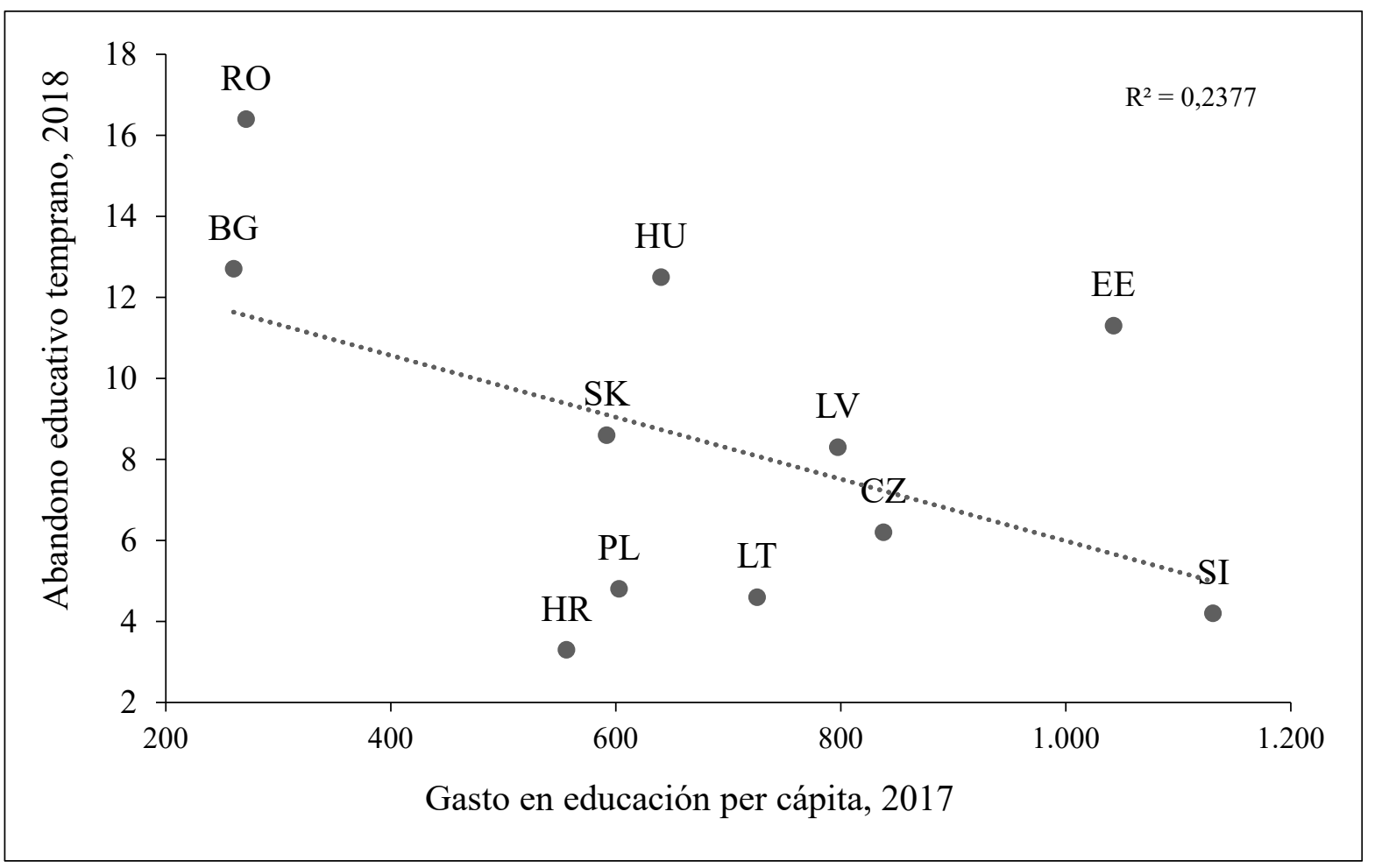

Fuente: Eurostat. Government expenditure by function. 
Gráfico 6. Relación tasa AROPE y el gasto en protección social en países de Europa del Este en UE-28, 2017 y 2018

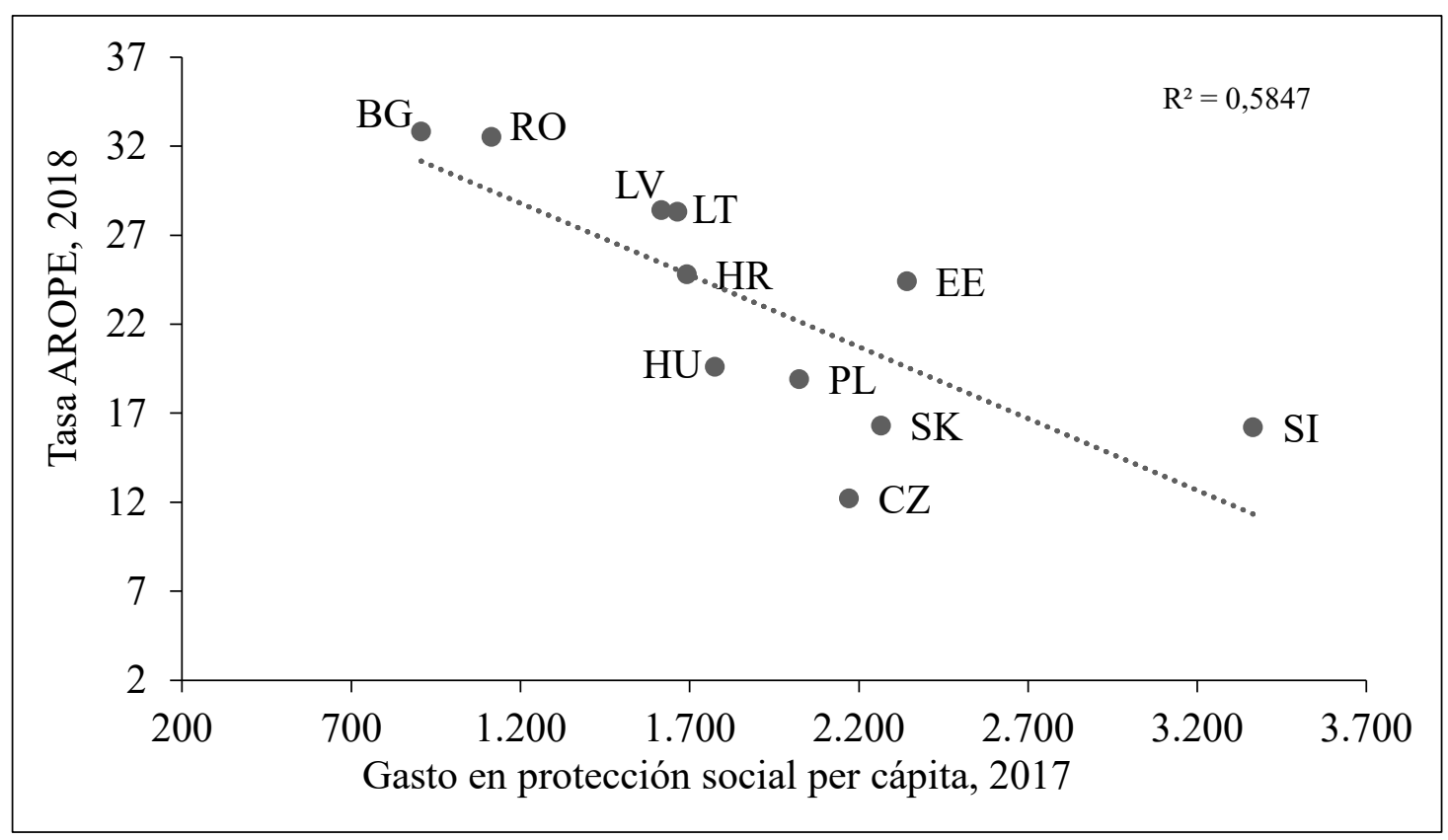

Fuente: Eurostat. Government expenditure by function.

de decisiones y políticas. La Unión Europea participa en coordinación con los Estados Miembros, aunque su función es más de coordinación y promoción de las políticas. El gasto social per cápita de las determinadas áreas de actuación nos puede aproximar al esfuerzo realizado en cada país para mejorar el bienestar de los ciudadanos, así como la eficiencia de ese gasto en relación con los resultados obtenidos (Cuadro 7).

El nivel de gasto en términos per cápita en los países de Europa del Este es muy inferior al que presenta el resto de los países de la UE-28. Con la excepción de Eslovenia, República Checa y Estonia, los demás países apenas llegan al 40\% de la media de la Unión. Rumanía y Bulgaria vuelven a copar los peores puestos del bloque, con un gasto que no llega al $20 \%$ de la media europea. Se observa un ligero aumento, tanto total como por partidas, en Europa del Este, pero la sensación es de estar a años luz del resto de sociedades europeas.

Más importante quizás que el nivel de gasto social per cápita es cómo se utiliza ese gasto: si se hace de manera eficiente y gracias a él se consiguen buenos resultados o si, por el contrario, no se obtienen buenos resultados, pese a realizar una importante inversión en las diferentes áreas de actuación.

Al poner en relación el gasto en educación realizado por cada gobierno y las tasas de abandono educativo temprano, se obtiene una relación negativa (Gráfico 5). Esta relación presenta un coeficiente de determinación, expresada por R2, del 0,2377 . De esta forma, la variabilidad en el abandono educativo temprano del conjunto de países analizados puede ser explicada en aproximadamente un $25 \%$ por el gasto público per cápita destinado a la educación, lo que indica que esta tasa está influida por otros factores, además del gasto social llevado a cabo en dicha área de actuación.

Aun así, esta relación permite obtener varias notas relevantes. Se observa que Rumanía y Estonia son los dos países que ejecutan un gasto más ineficiente, en dos situaciones diferentes. Por un lado, Rumanía invierte poco y es ineficiente $y$, por otro, Estonia, pese a ser el segundo país con el mayor gasto social en educación, presenta el cuarto peor resultado en el indicador de abandono educativo temprano. En el caso contrario tendríamos a Hungría, Polonia y Letonia como países más eficientes.

Asimismo, la relación entre la población en riesgo de pobreza o exclusión social y el gasto público per cápita en protección social del año 2018 (Gráfico 6) deja entrever varias conclusiones al respecto. En primer lugar, se obtiene una relación negativa, es decir, a mayor nivel de gasto menor riesgo de pobreza o exclusión social. Esta relación presenta un coeficiente de determinación del 0,5847. Es decir, la variabilidad en el riesgo de pobreza y exclusión social puede ser explicada aproximadamente en un $60 \%$ por la variabilidad del gasto en protección social. Esto significa que el gasto en protección social tiene una gran influencia en el riesgo de pobreza o exclusión social.

Vemos como son solo cuatro los países de Europa del Este eficientes en este sentido (Hungría, Polonia, Eslovaquia y Repú-

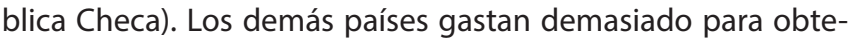
ner los resultados que obtienen. Nos volvemos a encontrar a 
Bulgaria y Rumanía como los países que menos gastan y de la forma menos eficiente, junto con Estonia.

\section{Conclusiones}

En base a los resultados obtenidos en los diferentes ámbitos que nos proporcionan la realidad socioeconómica de cada país es posible esbozar una serie de conclusiones sobre las dinámicas socioeconómicas de estos países.

\section{Evolución y tendencias dentro de Europa del Este}

Partir de las distancias entre los países de Europa del Este es determinante para considerar al bloque del Este como un modelo heterogéneo u homogéneo. Atendiendo a la evolución mostrada por los países de Europa del Este analizados y a las tendencias que se le atisban en el futuro, es posible caracterizar de heterogéneo a este grupo de países. Sin duda, las diferentes evoluciones se han visto condicionadas por los distintos efectos de la crisis, vinculados en gran medida a su inclusión o no en la zona euro y a las políticas de ajuste aplicadas (Observatorio Metropolitano de Madrid, 2011: 93).

En primer lugar, existen coincidencias en algunos ámbitos, como en el demográfico o en el de ingresos, en el que todos los países muestran una clara evolución y una reducción de las distancias. También en cuanto a la tasa AROPE, las diferencias se han reducido sustancialmente (3,5\% de media anual), impulsado en gran parte por las políticas de actuación y la Estrategia Europa 2020. Pese a ello, los resultados vertidos en los demás ámbitos invitan a asumir la existencia de diferentes submodelos de desarrollo socioeconómico.

Así, en términos de desigualdad de renta podemos advertir ahora una mayor diferencia entre los países de Europa del Este que al inicio de la crisis. Hungría, Lituania y Bulgaria han tenido aumentos en este indicador cercanos al $2 \%$ medio anual, mientras que la tendencia del resto de países de Europa del Este ha sido la de mantener unos resultados similares a los que ya tenía en 2008 .

También en el indicador de empleo a tiempo parcial involuntario las distancias han aumentado hasta el punto de desdibujar cualquier idea de considerar la existencia de un único modelo de empleo en Europa del Este. Los países que presentan una menor tasa, (Estonia, República Checa, Eslovenia, Polonia y Hungría), son también los únicos que la han reducido; mientras que los países con mayor nivel de población empleada involuntariamente a tiempo parcial (Rumanía y Bulgaria), han sufrido un aumento de la tasa.

En lo que se refiere al ámbito educativo, encontramos un aumento de las distancias entre los países del bloque del Este en los tres indicadores analizados. Si bien las distancias no han aumentado tanto como en otros ámbitos, sí invita a plantear la existencia de diferentes modelos educativos.

Por último, parece que las diferencias más acentuadas las encontramos en torno al modelo de gasto social de cada país. Las distancias entre países son muy elevadas y la tendencia no parece indicar que se estén reduciendo, sino que, en el caso del gasto en protección social, han aumentado. Serían Rumanía y Bulgaria los países que romperían más con la idea de bloque en cuanto a gasto social en Europa del Este, muy alejados ya no solo de los países con una mejor tendencia y situación como Eslovenia, República Checa o Estonia, sino alejados del resto de países que conforman este grupo.

\section{Convergencia hacia la UE-28}

El aumento o la reducción de las distancias que separan a los países de Europa del Este del resto de la UE-28 es fundamental a la hora de determinar si se están cumpliendo o no los principios de cohesión y si tenemos una tendencia a la conformación de una Europa homogénea o heterogénea.

A tenor de los indicadores analizados, podemos decir que, aunque existe convergencia con la Unión en ciertos ámbitos, como puede ser el de educación, el demográfico o el laboral, las distancias son tales en otros aspectos como el de gasto social o el económico que es difícil hablar de una convergencia real. Además, estas distancias se han ampliado durante la última década.

Desagregando por ámbitos, vemos que en el terreno económico el PIB per cápita sigue una tendencia de evolución y acercamiento a las medias europeas por parte de todos los países del bloque de Europa del Este, síntoma de un desarrollo económico constante. También lo ha sido en cuanto a la reducción de la pobreza. La Estrategia Europa 2020, en consonancia con el empleo de políticas europeas y nacionales, ha conseguido reducir en un gran porcentaje la población en riesgo de pobreza y exclusión social en todos los países con la excepción de Estonia. La diferencia con la UE se ha reducido a un ritmo del $13,6 \%$ de media anual, lo que constituye un gran logro alcanzado por los países de Europa del Este.

Es en la desigualdad de renta donde se concentra el aumento de la heterogeneidad dentro del bloque del Este en el ámbito económico. Las distancias en este indicador se han incrementado durante la última década en algo más de un $1 \%$ de media anual. La causa de esto se debe al incremento de la desigualdad en los países que ya eran los más desiguales de todo el Este de Europa: Bulgaria y Rumanía están más lejos de República Checa y Eslovenia que hace 10 años en términos de desigualdad de renta.

En el ámbito laboral, Europa del Este presenta ligeramente mejores datos en empleo que gran parte de la Unión Europea, debido fundamentalmente a los países bálticos, República Checa y Eslovenia. Es en la tasa de empleo a tiempo parcial involuntario donde se vuelven a ver, al igual que en la evolución de las distancias entre los países de Europa del Este, un mayor incremento de las diferencias entre estos últimos y la UE-28. 
Donde de nuevo se aprecian mayores disparidades es en el modelo de gasto social. Las distancias se incrementan más con respecto a la UE-28 que entre ellos pese a tener la Unión unos niveles mucho mayores de gasto. El crecimiento del gasto social en el bloque del Este ha sido mayor durante la última década que en el total de la Unión. Sin embargo, las distancias se han incrementado en más de un $2 \%$ de media anual en gasto en protección social y en torno al medio punto anual en gasto en educación.

Por tanto, podemos concluir que los principales factores de divergencia con la Unión Europea se encuentran en la desigualdad de renta, la calidad del empleo y el nivel de gasto social. Serían estos puntos, además de la situación de inicio de la que parten los países de Europa del Este, los que estarían frenando el deseado proceso de convergencia.

Evolución del cumplimiento de los objetivos

El cumplimiento de los objetivos Europa 2020 ha estado condicionado por la crisis económica según los diferentes informes de seguimiento de los objetivos. A poco más de un año de la conclusión de esta Estrategia, todo parece indicar que su adopción fue excesivamente ambiciosa y no se adecua a la realidad de los distintos países, ni a los medios de los que dispone la Unión para impulsar su consecución.

En cuanto a los objetivos que han sido parte de este análisis, podemos establecer diferentes grados de cumplimiento. Respecto a la tasa AROPE, donde la UE cifraba el objetivo en la reducción de 20 millones de europeos en riesgo de pobreza y exclusión social, lo que en términos relativos significaba reducir esa tasa a un 19\% en todo el espacio europeo, se puede hablar de fracaso. Siete de los once países que conforman el bloque de Este quedan bastante por encima de ese objetivo, así como la propia media de la UE-28. Los cuatro países que se sitúan por debajo de ese 19\% son Eslovenia, República Checa, Eslovaquia y Polonia.

En lo que incumbe al ámbito laboral, la Unión Europea dispuso como objetivo elevar la tasa de empleo para los países de la Unión a un $75 \%$. Seis de los once países del bloque no han llegado a esos niveles, donde preocupa especialmente el caso de Croacia que se ha quedado a 10 puntos porcentuales de ese objetivo. Los países que sí lo han cumplido vuelven a ser, por un lado, Eslovenia y República Checa; y, por otro, las tres repúblicas bálticas de Estonia, Letonia y Lituania.

Por último, y en lo que refiere al aspecto educativo, la UE fijó sus intenciones para la nueva década en reducir las tasas de abandono educativo temprano, cifrándola en un 10\% para el total de la población europea. Aquí sí que podemos hablar de un cumplimiento más o menos generalizado ya que siete de los once países presentan unos niveles inferiores a ese $10 \%$. Estonia, Hungría, Bulgaria y Rumanía serían los países que se quedarían alejados con respecto a la consecución de este objetivo. La propia UE-28 tampoco lograría su cumplimiento.
Propuestas de modelización

Teniendo en cuenta las diferentes situaciones de desarrollo socioeconómico y a las evoluciones y tendencias de convergencia con la UE-28 mostradas por los países de Europa del Este durante la última década, podemos plantear la existencia de cuatro diferentes modelos dentro del bloque analizado: modelo del Este-Centroeuropeo, modelo del Este Oriental, modelo báltico y modelo del arco del Mar Negro.

El modelo del Este-Centroeuropeo esta integrado por Eslovenia y República Checa. Estos dos países, miembros de la Unión desde 2004, presentan una buena situación socioeconómica, liderando al bloque de Este en términos de desarrollo. Son los países con mayor renta per cápita, con unos niveles muy cercanos a los de las economías menos desarrolladas de la UE-15. También poseen los dos Índices de Desarrollo Humano más altos, llegando a superar a países como España, Italia o Portugal. Además, se trata de los dos únicos países de Europa del Este que han conseguido cumplir con los tres objetivos de la Estrategia Europa 2020 analizados en este estudio. La Comisión Europea ya los consideraba los países con más posibilidades de lograr una integración real en la UE antes de llevar a cabo su adhesión. Aidukaite (2009) y Potucek (2008) los definen como países que combinan seguros sociales de estilo Bismarck con una tributación universal escandinava. Este modelo encontraría sus notas definitorias en un gran modelo de empleo, con escaso paro y población con empleo a tiempo parcial involuntario, acompañado de unos muy buenos resultados en educación, y los mejores datos en términos de renta, desigualdad y pobreza, llegando a presentar una mejor situación que la de la UE-28 en ciertos aspectos.

En el lado contrario, como modelo más alejado de lograr una cohesión social y económica efectiva con el resto de la Unión, encontraríamos a los países del arco del Mar Negro (Rumanía y Bulgaria), miembros desde el año 2007. Estos países mostrarían la peor situación de desarrollo, no solo del bloque del Este, sino de toda Europa. Son los países que muestran los peores resultados en las tres áreas de estudio. El PIB per cápita en esta región apenas llega al 50\% de la media de la UE-28 y, además, viene acompañado de las tasas AROPE y de desigualdad más elevadas de todos los países analizados. Sus niveles de desarrollo sintetizados por el IDH constatan los peores resultados de toda la UE-28, a la altura de países que no forman parte de la Unión como Bosnia o Montenegro. Sin embargo, se atisba un tímido intento de luchar por la integración por parte de estos dos países que se refleja en los grandes esfuerzos para reducir el nivel de población en riesgo de pobreza o exclusión social, aumentar el PIB per cápita o el gasto en protección social, donde han experimentado mayores crecimientos que el resto de Europa. La Comisión Europea, en el informe antes mencionado, ya los consideraba como los dos países que iban a mostrar más dificultades para integrarse. Fenger (2007) los agrupa con Rusia, Ucrania o Macedonia, como países que están evolucionando hacia el liberalismo económico y la residualización del Estado de Bienestar. Uno de los entrevistados se refería así a la tendencia y posible futura evolución de estos dos países: 
Rumanía y Bulgaria solo pueden ir a mejor. Están haciendo un gran esfuerzo por la industrialización y la internacionalización. Llegar a un modelo social que, aunque con tintes liberales, sea medianamente solvente y fuerte les va a costar mucho más. Sus instituciones están muy condicionadas por las relaciones informales (E3, Sociología).

Por último, en un nivel de integración en la UE y de desarrollo socioeconómico que podríamos valorar de medio, encontraríamos dos modelos que responden a unas características diferentes. Por un lado, un modelo del Este Oriental, conformado por Polonia, Hungría, Eslovaquia y Croacia. Estos países han tenido un gran crecimiento durante la última década, sobre todo en términos económicos y en reducción de la pobreza, pese a que Croacia ha resultado muy afectado por la crisis económica, sobre todo en su modelo laboral que ha seguido unas tendencias similares a las de los países mediterráneos.

Finalmente, las tres repúblicas bálticas conformarían el cuarto modelo. Estos tres países (Estonia, Letonia y Lituania) están unidos por varios lazos históricos y de contexto. De los países analizados, estos fueron los únicos que formaron parte de facto de la antigua Unión Soviética, lo que ha dejado rastros en la configuración actual de estos países. Estos países comparten un gran crecimiento económico en la última década, sobre todo en el caso de Estonia y Lituania, que poseen dos de las rentas per cápita más altas de todo el bloque. Sin embargo, este desarrollo económico viene acompañado de un elevado porcentaje de población en riesgo de pobreza y exclusión social, y de desigualdad en la distribución de la renta. Comparten unos grandes resultados educativos, tanto en términos de población con estudios secundarios como terciarios, acompañado de un gasto en educación superior a la media. Como comentábamos en el texto, se trata de una herencia del sistema comunista que pretendía que la educación fuera universal en todos sus niveles.

Retos para la cohesión económica y social en la UE

Los diferentes análisis realizados (cuantitativos y cualitativos) permiten identificar los principales retos para el logro de la integración de los países de Europa del Este en la UE, logrando así la cohesión económica y social. Alcanzar esta integración es realmente importante, ya que, entre otras cosas, implicaría el cumplimiento del principio de no discriminación previsto en los Tratados. Además, si la Unión pretende crear un espacio de justicia, libertad y seguridad y elevar el bienestar de los pueblos de Europa como disponen los tratados, la integración de Europa del Este juega un papel fundamental.

En este sentido, los retos que tiene por delante la Unión serían aquellas esferas en las que no se ha logrado una convergencia desde que los países de Europa del Este se adhirieran a la Unión. Podemos concluir que las principales áreas en las que estos países se están alejando del resto de la UE-28 son la desigualdad, la calidad del empleo y las políticas institucionales en términos de gasto social. Además, y pese a que la tendencia es a converger, la renta per cápita de los países de Europa del Este se encuentra muy alejada de la de la Unión y los desiguales ritmos de crecimiento han provocado un mayor distanciamiento en varios ámbitos entre los propios países de Europa del Este.

Para lograr estos objetivos, una de las posibilidades que puede manejar la Unión es el empleo de sus fondos propios, como las ayudas regionales, o dirigir los fondos nacionales hacia objetivos comunes. Los países de Europa del Este han sido principal objetivo de esas ayudas durante varios años, pero no todos las han gestionado igual, por lo que cabría culpar a un problema institucional propio de cada país. En este sentido los entrevistados destacan la necesidad de ampliar las competencias de la UE, tanto a nivel político como económico.

La Unión Europea debería tener más competencias en materia económica y fiscal. Creo que deberíamos tender a presupuestos europeos y políticas de armonización de fiscalidad directa de empresas. Los llamados 'tax ruling' donde multinacionales pagan un euro por millón de euros de beneficios en Irlanda, por ejemplo, causan un daño a la cohesión enorme, ya que son una pérdida de recursos fiscales (E4, Derecho Internacional).

Tener un gobierno que pueda manejar un presupuesto y que pueda actuar en cualquier país de la Unión para neutralizar determinados movimientos puede permitir cohesionar las sociedades y salir al paso de los movimientos de desconexión. Si eso no sucede, tenemos riesgo de que la no cohesión y la desafección de los ciudadanos de la Unión vaya a más (E2, Economía).

La UE ha intentado la adquisición de estas competencias, la última mediante una directiva en el año 2016. Sin embargo, la existencia de un lobby formado por los países más ricos de la UE que traba sus decisiones, sumado a la posible negativa de los países de Europa del Este a perder una soberanía y una identidad nacional que tanto tiempo les ha llevado conseguir, dificulta que se pueda alcanzar una mayor potestad de la Unión ya que se requiere unanimidad por parte de todos los Estados miembros. Además, el nacimiento de movimientos euroescépticos en ciertos países del Este, como Polonia o Hungría, complican aún más la obtención de competencias por parte de la UE. 
Bibliografía

AIDUKAITE, J. (2009): "Old Welfare State Theories and New Welfare Regimes in Eastern Europe", Communist and Post-Communist Studies, 42, pp. 23-39.

AJA VALLE, J. (coord.) (2014): Cambiar Europa. Confluencias políticas y sociales en una Europa en Crisis. Madrid, Fundación Europa de los ciudadanos.

ALESINA, A. y PEROTTI, R. (1996): "Income distribution, political instability and investment", European Economic Review, 40(6), pp. 1.203-1.228.

ARRIOLA, J. (2014): La estrategia de la Unión Europea de lucha contra la pobreza. Documento de Trabajo 8.2. Madrid, Fundación FOESSA

BAVIERA, I. (2010): "Las políticas de empleo en la Unión Europea: una reflexión en el vigésimo aniversario de la caída del muro de Berlín", Empresa y Humanismo, 13(2), pp. 67-78.

CALATRAVA LESMES, O. (2018): “¿Está en cuestión el modelo social europeo?", Revista de Derecho UNED, 23, pp. 287-314.

CASTLES, I. (1998): "The Mismeasure of Nations: A Review Essay on the Human Development Report 1998", Population and Development Review, 24(4), pp. 831-845.

CUADRADO, J. R y MARCOS, M.A (2005): “Disparidades regionales en la Unión Europea. Una aproximación social a la cuantificación de la cohesión económica y social", Investigaciones Regionales, 6, pp. 63-89.

COMISIÓN EUROPEA (2010): Europa 2020. Una estrategia para un crecimiento inteligente, sostenible e innovador. Comunicación de la Comisión Europea.

COMMISSION OF THE EUROPEAN COMMUNITIES (2009): "Progress towards the Lisbon objectives in education and training". Commission of the European Communities.

CONSEJO EUROPEO DE LISBOA (2000): Conclusiones de la Presidencia. Lisboa, 23 y 24 de marzo.

DELORS, J. (1993): El nuevo concierto europeo. Madrid, Acento.

DE PABLOS, J. y MARTÍNEZ, A. (2008): "La Estrategia Europea de Empleo: Historia, consolidación y claves de interpretación", Revista del Ministerio de Trabajo e Inmigración, 77, pp. 105-133.

EGIDO, I. (1996): "La política educativa de la Unión Europea: principales etapas de desarrollo", Tendencias pedagógicas, 2, pp. 19-29.

EICHHORST, W.; FELI, M. y MARX, P. (2010): "Crisis, What Crisis? Patterns of Adaptation in European Labour Markets", IZA Discussion Paper. $\mathrm{n}^{\circ}$ 5.045 .

ENAMORADO, T., LÓPEZ-CALVA, L. F., RODRÍGUEZ-CASTELÁN, C., y WINKLER, H. (2016): "Income inequality and violent crime: Evidence from Mexico's drug war", Journal of Development Economics, 120, pp. 128-143.

ESPING-ANDERSEN, G. (1993): Los tres mundos del Estado del Bienestar. Valencia, Edicions Alfons el Magnanim.

EUROPEAN COMMISION (2018): Methodological manual on territorial typologies. European Commision Communication.

FANTOVA AZCOAGA, F. (2014): Diseño de políticas sociales. Fundamentos, estructura y propuestas. Madrid, Editorial CCS.

FARINÓS, J. (2008): "Gobernanza territorial para el desarrollo sostenible: estado de la cuestión y agenda", Boletín de la Asociación de Geógrafos Españoles, 46, pp. 11-32.

FENGER, M. (2007): "Welfare Regimes in Central and Eastern Europe: Incorporating Post-Communist Countries in a Welfare Regime Typology", Contemporary Issues and Ideas in the Social Sciences, 3(2), pp. 1-30.

FERRERA, M. (1998): "The four social Europes: between universalism and selectivity", en M. Rhodes e Y. Meny (eds.), The Future of European Welfare. London: Palgrave MacMillan, pp. 81-96.

FORMICHELLA, M. M. y LONDON, S. (2013): "Empleabilidad, educación y equidad social", Revista de estudios sociales, 47, pp. 79-91.
HERNÁNDEZ PEDREÑO, M. (2010): "El estudio de la pobreza y exclusión social. Aproximación cuantitativa y cualitativa", Revista interuniversitaria de formación del profesorado, 69, pp. 25-46.

HERNÁNDEZ PEDREÑO, M. y GARCÍA LUQUE, O. (2017): "Modelos sociales en Europa: ¿convergencia o divergencia tras la crisis?", Áreas. Revista Internacional de Ciencias Sociales, 36, pp. 55-71.

LOIS, R. C., FEAL, A. y CARRIL, V (2013): “La dimensión territorial de la Estrategia Europa 2020. Las regiones europeas en la senda oficial para salir de la crisis", Ería, 92, pp. 211-242

MALGESINI, G. (2017): Seminario Inclusión social en el medio rural en España y Europa. Madrid, EAPN España.

MANCERO, X. (2001): “La medición del desarrollo humano: elementos de un debate", CEPAL, Serie de Estudios Estadísticos y Prospectivos.

MIGUÉLEZ, F. (2007): "Flexiseguridad, bienestar y cohesión social" Revista del Ministerio de Trabajo y Asuntos Sociales, Número Extraordinario 1, pp. 145-160.

MIGUÉLEZ, F. y PRIETO, C. (2008): "Transformaciones del empleo, flexibilidad y relaciones laborales en Europa", Política y Sociedad, 46 (1 y 2), pp. 275-287.

MORENO FERNÁNDEZ, L. (2012): La Europa Asocial. ¿Caminamos hacia un individualismo posesivo? Barcelona, Península.

MORENO FERNÁNDEZ, L. (2017): "La viabilidad del modelo social europeo”, Razón y Fe, 1.421, pp. 227-237.

MORENO FERNÁNDEZ, L. (2017): "El entorno europeo y global de los sistemas de bienestar", Documentación social, 186, pp. 15-31.

MORENO FERNÁNDEZ, L. y SERRANO PASCUAL, A. (2007): “Europeización del Bienestar y activación", Política y Sociedad, 44(2), pp. 31-44.

MULAS-GRANADOS, C. (2009): "Globalización, modelo social europeo y estado dinamizador", en F. Beltrán (coord.), Modelos sociales europeos. Madrid, Marcial Pons, pp. 95-104.

OBSERVATORIO METROPOLITANO DE MADRID (OMM) (2011): Crisis y revolución en Europa. Madrid, Observatorio Metropolitano de MadridTraficantes de sueños.

ORGANIZACIÓN DE LAS NACIONES UNIDAS (ONU) (1990): Human Development Report 1990.

PARAMIO, L. (2009): “El modelo europeo: ¿modelo económico o modelo social?", Nueva sociedad, 221, pp. 166-179.

POTUCEK, M. (2008): "Metamorphoses of Welfare States in Central and Eastern Europe", en M. Seeleib-Kaiser (ed.). Welfare State Transformations: Comparative Perspectives, New York, Palgrave Macmillan, pp. 79-95.

SANAHUJA, J. A. (2012): "Las cuatro crisis de la Unión Europea", en M. Mesa (coord.), Cambio de ciclo: crisis, resistencias y respuestas globales. Madrid, CEIPAZ-Fundación Cultura de Paz, pp. 51-83.

SHACKLETON, J. R. (2009): “'Se ha pasado el momento del modelo social europeo?", en F. Beltrán (coord.), Modelos sociales europeos. Madrid, Marcial Pons, pp. 69-94.

SÁNCHEZ DE GÓMEZ, L. (2011): "Evolución histórica de la cohesión económica y social en la Unión Europea", Revista de Estudios Empresariales, 2, pp. 4-28.

SAPIR, A. (2006): "Globalisation and the Reform of European Social Models", JCMS, 44(2), pp. 369-390.

ZAIDI, A. (2008): "Features and Challenges of Population Ageing: The European Perspective", Policy Brief March, 1, pp. 1-16. 